\title{
Government Policy Response to War-Expenditure Shocks
}

\author{
Fernando M. Martin
}

\author{
Working Paper 2011-028A \\ https://doi.org/10.20955/wp.2011.028
}

October 2011

\author{
FEDERAL RESERVE BANK OF ST. LOUIS \\ Research Division \\ P.O. Box 442 \\ St. Louis, MO 63166
}

The views expressed are those of the individual authors and do not necessarily reflect official positions of the Federal Reserve Bank of St. Louis, the Federal Reserve System, or the Board of Governors.

Federal Reserve Bank of St. Louis Working Papers are preliminary materials circulated to stimulate discussion and critical comment. References in publications to Federal Reserve Bank of St. Louis Working Papers (other than an acknowledgment that the writer has had access to unpublished material) should be cleared with the author or authors. 


\title{
Government Policy Response to War-Expenditure Shocks
}

\author{
Fernando M. Martin* \\ Federal Reserve Bank of St. Louis and Simon Fraser University
}

October 6, 2011

\begin{abstract}
A theory of government policy determination, based on intertemporal distortion-smoothing and limited commitment, matches the set of stylized facts of U.S. wartime policy.
\end{abstract}

Keywords: government policy, limited commitment, U.S. wars, money micro-foundations.

JEL classification: E13, E52, E62, E63, H60

\begin{abstract}
*Email: fernando.m.martin@stls.frb.org. I'd like to thank the editor, Nicola Pavoni, and three anonymous referees for numerous helpful comments and suggestions. I thank seminars participants at the Federal Reserve Bank of St. Louis, the Society for Economic Dynamics, and the Chicago Fed Workshop on Money, Banking Payments and Finance. I gratefully acknowledge financial support from the SFU/SSHRC Institutional Grants Committee. The views expressed in this paper do not necessarily reflect official positions of the Federal Reserve Bank of St. Louis, the Federal Reserve System, or the Board of Governors.
\end{abstract}




\section{Introduction}

Since its inception, the U.S. has experienced three episodes in which public expenditure temporarily increased to very high levels: the Civil War, World War I and World War II. Of interest to economists, these wars share a set of stylized facts regarding the response of government policy. First, debt, inflation and tax revenue all increased during wartime. Second, the debt response was large and persistent, more so than any other policy variable. Third, there were large wartime deficits followed by persistent peacetime surpluses. Fourth, depending on the monetary system in place, once the war ended, prices either returned to pre-war levels or continued to increase to partially finance the accumulated debt. Fifth, output increased significantly during wartime.

The classic tax-smoothing model proposed by Barro (1979) rationalizes the large and persistent increase in debt. However, it fails to explain the contemporaneous increase in taxes, since the theory dictates that tax distortions should be spread across time and states of world. The same result obtains in a standard Ramsey (commitment) model of optimal taxation with incomplete markets - see for example Aiyagari et al. (2002).

If we incorporate monetary policy, as in Lucas and Stokey (1983), Chari et al. (1991) and Aruoba and Chugh (2010), among others, then the tax-smoothing argument generalizes to stabilizing the nominal interest rate as well. The government uses monetary policy to make debt state-contingent, effectively completing markets. As a result, we get no persistence in debt and the response goes in the wrong direction. In addition, inflation is too volatile, with zero or negative autocorrelation. The failure of complete markets models in accounting for the stylized behavior of U.S. policy variables is addressed more generally by Marcet and Scott (2009). ${ }^{1}$

As argued in Martin (2009), relaxing the commitment assumption-which brings us back to an incomplete markets economy - allows standard tax-smoothing models to explain both the mix of financing instruments used to pay for temporary increases in expenditure, and the large and persistent response in debt. The analysis, however, does not cover the behavior of deficits and output, leaving some important empirical regularities of wartime financing unexplored. In addition, the numerical simulations predict either implausibly low or high levels of inflation, and a counterfactual postwar behavior in tax revenue.

In this paper, I present a theory of government policy that matches qualitative and quantitative facts of U.S. wartime policy. As in Martin (2009), the key friction is the government's inability to commit to policy actions beyond the current period. A notable theoretical difference is that here, the underlying monetary economy is a variant of the micro-founded framework proposed by Lagos and Wright (2005), as opposed to the reduced-form approach of cash-in-advance. ${ }^{2}$ In addition, the quantitative treatment in this paper is, as far I know, the first systematic attempt to match a model of government policy to the combined set of stylized facts of U.S. wartime financing.

\footnotetext{
${ }^{1}$ The policy response in other countries may not conform to the U.S. experience. For example, Aiyagari et al. (2002) suggest that Lucas and Stokey's model may be better suited to explain French policy in the 18th century. Similarly, Shin (2007) shows that the complete markets Ramsey allocation can be implemented with active maturity management in a way that resembles British 18th century policy.

${ }^{2}$ Monetary theorist have long argued that many key results and interesting insights are missed by adopting a reduced-form approach - see Wallace (1998, 2001), Shi (2006) and Williamson and Wright (2010), among others. Furthermore, policy recommendations may be sensitive to the details of the environment and, in this sense, microfounded models of money address a version of the Lucas critique (Lucas, 1976).
} 
The mechanism determining government policy works as follows. With limited commitment, the government still has incentives to smooth distortions intertemporally. However, the gains from such a policy are weighted against a time-consistency problem created by the interaction between debt and monetary policy. Specifically, how much debt the government inherits affects its monetary policy since inflation reduces the real value of nominal liabilities. In turn, the anticipated response of future monetary policy affects the current demand for money and bonds, and thereby how the government today internalizes policy trade-offs. Martin $(2011 a, b)$ analyze the theoretical and quantitative properties of this mechanism, in the context of the Lagos-Wright framework.

I evaluate the merits of the proposed theory in explaining U.S. wartime policy in several steps. First, I calibrate the artificial economy to post-war U.S. and show that the policy response to war-expenditure shocks matches the enumerated stylized facts qualitatively. Second, I simulate the model for a large number of periods and show that the policy response falls within the ranges observed in the three war episodes considered. I also show that whether the increase in expenditure occurs sudden or gradually affects the quantitative policy response. Third, to provide a sharper evaluation of the quantitative merits of the model, I simulate World War II and directly compare the modeled response with the data. The model performs well quantitatively, although it over-relies on tax revenue, as opposed to deficit financing, and predicts a bit too much inflation. Finally, I use the simulation to interpret the abnormal policy implemented during the subsequent Korean War, which was almost entirely financed with tax revenue. I argue that this episode is consistent with a tax-smoothing model with limited commitment, as long as we assume that the increase in government expenditure was perceived as permanent, rather than transitory.

The results in this paper complement empirical studies on U.S. wartime policy, such as Goldin (1980), Balke and Gordon (1986), Ohanian (1997, 1998) and McGrattan and Ohanian (2010). The analysis here provides a theoretical explanation for the behavior documented in this literature. It also provides further support to the hypothesis that limited commitment is a key friction in the determination of actual government policy. Coupled with the related analyses in Martin $(2011 a, b)$, we now have a theory of government that, within a micro-founded monetary framework, explains several aspects of policy during normal times, as well as during infrequent but significant episodes, such as wars.

The paper is organized as follows. Section 2 describes stylized facts of U.S. wartime policy. Section 3 presents the theoretical model and characterizes government policy. Section 4 conducts the numerical evaluation. Section 4 concludes.

\section{Stylized facts of wartime U.S. policy}

Figure 1 displays select policy variables for the U.S. between 1791 and 2010. ${ }^{3}$ Periods with temporarily high defense outlays due to wars are highlighted (see Appendix A): the War of 1812, the Mexican-American War, the Civil War, World War I, World War II, the Korean War, the Vietnam War and the Afghanistan-Iraq wars. Note that for the Vietnam War, only the period 1967-1969 is highlighted since it is during these years that defense expenditure temporarily increases; except for this brief period, defense expenditure over GDP actually decreased steadily throughout the 60s

\footnotetext{
${ }^{3}$ The data is taken from Wallis (2006a), Wallis (2006b), Lindert and Sutch (2006), Johnston and Williamson (2008), the Bureau of Labor Statistics and the Office of Management and Budget, as described in Martin (2009).
} 
Figure 1: U.S. government policy: 1791-2010
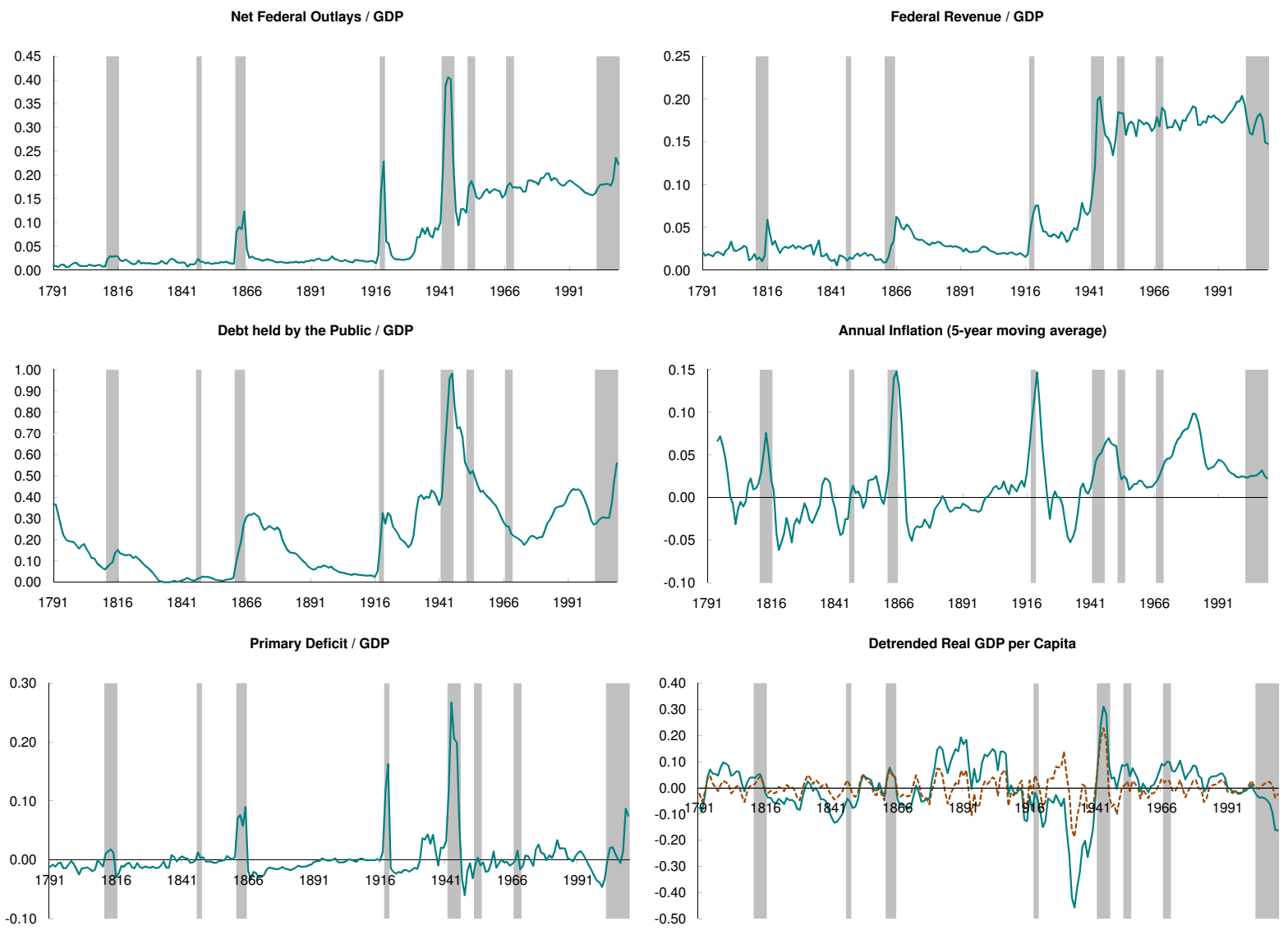

Note: Periods with temporarily high defense outlays due to wars are highlighted-see Figure 4 in Appendix A. Real GDP per capita is detrended using a quadratic polynomial (solid line) and an HP-filter with a smoothing parameter of 100 (dashed line).

and 70s. The wars in Afghanistan and Iraq which started in 2001 and 2003, respectively, implied a modest but steady increase in defense outlays - only about 1.7 percentage points in terms of GDP by 2010. Most of the increase in total government expenditure in the first decade of the 21st century is due to non-defense items.

Let us focus on the three episodes which involved a sizable increase in government expenditure: the Civil War and the two World Wars. These episodes share several stylized facts, which will guide the analysis in the paper.

First, all three wars were financed with contemporaneous increases in debt, tax revenue and inflation. Goldin (1980) estimates that the contribution of debt and seignorage to war financing was 91\% for the Civil War, 76\% for World War I and 59\% for World War II, with the rest being financed with contemporaneous taxes. Other past war episodes have followed a similar pattern (observe, for example, the policy response during the War of 1812), with the notable exception of the Korean War, which in contrast, was almost exclusively financed with contemporaneous taxes - see Ohanian (1997) and the discussion in Section 4.4. 
Second, the increase in debt is large and persistent. In fact, debt displays the largest and most persistent response among all policy variables. Recently, Marcet and Scott (2009) and Martin (2011a) document that the persistence of debt relative to other policy variables is also a property of the post-war U.S. economy.

Third, corresponding to the behavior of taxes and debt, there is a sharp increase in the primary deficit during wartime, followed by a persistent post-war surplus. Furthermore, tax revenues remain at high levels longer than expenditure.

Fourth, inflation partly finances the temporary increase in expenditure and may also be used to reduce accumulated debt. Ohanian (1998) identifies the recurring pattern of significant inflation financing of war expenditure. In episodes preceding World War II, convertibility of the dollar to gold and/or silver would be suspended during wartime, and prices would return to pre-war levels afterward. In contrast, the increase in prices during World War II was permanent. Furthermore, there was a significant post-war inflation (1946-1948) which, according to Ohanian's calculations, implemented a repudiation of debt equivalent to about $40 \%$ of GNP.

Fifth, real GDP increases during wars. While real GDP per capita grew at $1.5 \%$ annually between 1791 and 1929, it grew at 3.3\% and 2.5\% annually, during the Civil War and World War I, respectively. Real GDP per capita grew 2.6\% annually between 1933 and 2010; during World War II, growth was $10.3 \%$ annual.

Table 1 focuses on the three main wars discussed above and offers an alternative way of analyzing the government policy response to war-expenditure shocks. For each variable, the table displays the difference between the peak value during wartime and the average of the preceding five years. This is a measure of the amplitude of policy response and will be used below to evaluate the performance of the theoretical model.

Table 1: War peak vs 5-year pre-war average

\begin{tabular}{|l|c|c|c|}
\hline & Civil War & World War I & World War II \\
\hline Policy variable & 0.108 & 0.208 & 0.322 \\
Outlays / GDP & 0.021 & 0.048 & 0.135 \\
Revenue / GDP & 0.087 & 0.160 & 0.252 \\
Deficit / GDP & 0.258 & 0.292 & 0.579 \\
Debt / GDP & 0.243 & 0.122 & 0.097 \\
Inflation \\
\hline Detrended real GDP per capita \\
\hline Linear & 0.075 & 0.060 & 0.500 \\
Quadratic & 0.086 & 0.057 & 0.485 \\
HP-filter & 0.096 & 0.071 & 0.279 \\
HP-filter (Ravn-Uhlig) & 0.063 & 0.058 & 0.137 \\
\hline
\end{tabular}

Note: For each variable, the table displays peak value during wartime minus the average of the 5 preceding years. The wartime period includes the year following the end of the war, to capture variables that may peak with a lag.

For GDP per capita, four measures are presented, each corresponding to a different detrending method: linear, quadratic, HP-filter with a the standard smoothing parameter of 100 and HP- 
filter with the smoothing parameter suggested by Ravn and Uhlig (2002) (6.25). Regardless of the detrending method used, there is a large increase in GDP during wartime. The reason for presenting multiple measures of GDP growth is that output may display low frequency movements that are unrelated to a war-episode. This is a special concern during World War II, where the methods differ significantly, since they handle the Great Depression in different ways. In particular, the HP-filter with a smoothing parameter of 6.25 interprets a significant part of GDP growth during World War II as an ongoing change in trend rather than cycle.

To put some perspective on these numbers, Balke and Gordon (1986) compute a "natural" series for output and estimate that GNP was $27 \%$ above trend at the peak of World War II, in 1944. On the other hand, Ohanian (1997) reports 40\% growth in real GNP between 1941 and 1945. Taking these previous results into consideration, I will henceforth focus on real GDP per capita, detrended with a quadratic polynomial (since it improves fit over linear) and with an HP-filter with a smoothing parameter of 100 .

\section{Theoretical framework}

This section presents a model of government policy in the presence of expenditure shocks, following Martin $(2011 a, b)$. The underlaying economy is a variant of the micro-founded monetary framework by Lagos and Wright (2005).

\subsection{Environment}

The economy consists of a continuum of infinitely lived agents and a benevolent government that supplies a valued public good $g .{ }^{4}$ To finance its expenditure, the government may use proportional labor taxes $\tau$, print fiat money at rate $\mu$ and issue one-period nominal bonds, which are redeemable in fiat money. Agents derive utility from the public good according to $\psi v(g)$, where $v$ is twice continuously differentiable, satisfies Inada conditions, $v_{g}>0>v_{g g}$ and $\psi$ is a random variable following a Markov process. Let $\Psi$ be the (compact) set of all possible realizations of $\psi$ and use $E[. \mid \psi]$ to denote the conditional expectation of future variables given the current state $\psi$. When conducting the numerical evaluation of the theory, $\psi$ will be typically low and stable, denoting "peacetime", and "wars" will be interpreted as consecutive periods where $\psi$ is temporarily high.

Each period, two competitive markets open in sequence: a "day" and a "night" market. At the beginning of the period, agents receive an idiosyncratic shock that determines their role in the day market. With probability $\eta \in(0,1)$ an agent wants to consume but cannot produce the (perishable) day-good, $x$, while with probability $1-\eta$ an agent can produce but does not want consume. A consumer derives utility $u(x)$, where $u$ is twice continuously differentiable, satisfies Inada conditions and $u_{x}>0>u_{x x}$. A producer incurs in utility cost $\phi x$, with $\phi>0 .{ }^{5}$ Agents lack commitment and are anonymous, in the sense that their trading histories are unobservable. Thus, credit transactions between agents are not possible. Since there is a lack of double coincidence of

\footnotetext{
${ }^{4}$ The assumption that $g$ is valued is made for analytical convenience. We can conduct the same type of analysis using exogenous expenditure.

${ }^{5}$ The disutility from producing in the day can be generally written as a convex function of $x$. A linear specification reduces the number of parameters that we need to calibrate.
} 
wants problem, some medium of exchange is essential for trade to occur - see Kocherlakota (1998), Wallace (2001) and Shi (2006), among others.

There exist financial institutions ("banks") endowed with a technology that allows them to record financial (but not trade) histories at zero cost, as in Berentsen et al. (2007). ${ }^{6}$ Banks cannot issue their own notes, nor can they provide third-party verification for government bonds in transactions between agents. At the beginning of each day, sellers can deposit their money holdings at banks, and buyers can borrow money from banks. Deposits $d$ and loans $l$ mature at night. Perfect competition in the banking sector implies that the deposit and loan interest rates are equal. Let $i \geq 0$ be the bank nominal interest rate. Assume perfect enforcement and no borrowing constraints in financial markets.

At night, all agents can produce and consume a (perishable) night-good, $c$. The production technology is assumed to be linear in hours worked, $n$. Utility from consumption is given by $U(c)$, where $U$ is twice continuously differentiable, satisfies Inada conditions and $U_{c}>0>U_{c c}$. Disutility from labor is given by $\alpha n$, where $n$ is hours worked and $\alpha>0$. Assume the following regularity condition holds: $U_{c c} c-\left(U_{c}-\alpha\right)\left(1+\frac{U_{c c c} c}{U_{c c}}\right)<0$ for all $c \in(0, \hat{c}]$ - note that the typically adopted $U(c)=\frac{c^{1-\rho}}{1-\rho}$, with $\rho>0$, satisfies this requirement.

The first-best state-contingent allocation is given by $\{\hat{x}, \hat{c}, \hat{g}(\psi)\}$, where $u_{x}(\hat{x})=\phi, U_{c}(\hat{c})=\alpha$ and $\psi v_{g}(\hat{g}(\psi))=\alpha$, for all $\psi \in \Psi$.

The government only actively participates in the night-market, i.e., taxes are levied on hours worked at night and open market operations are conducted in the night market. As in Aruoba and Chugh (2010), Berentsen and Waller (2008) and Martin (2011b), public bonds are book-entries in the government's record. Since bonds are not physical objects and the government does not participate in the day market (i.e., cannot intermediate or provide third-party verification, which also prevents banks from intermediating debt), bonds are not used as a medium of exchange in the day market and thus, fiat money is essential.

All nominal variables - except for bond prices - are normalized by the aggregate money stock. Thus, today's aggregate money supply is equal to 1 and tomorrow's is $1+\mu$. The government budget constraint is

$$
1+B+p g=p \tau n+(1+\mu)\left(1+q B^{\prime}\right),
$$

where $B$ is the current aggregate bond-money ratio, $p$ is the - normalized-market price of night output, $n$ is labor and $q$ is the discount price of a one-period bond that earns a unit of fiat money. "Primes" denote variables evaluated in the following period. Thus, $B^{\prime}$ is tomorrow's aggregate bond-money ratio.

The government lacks the ability to commit to future policy choices and announces policy $\left\{B^{\prime}, \mu, \tau, g\right\}$ at the beginning of each period, after observing the level of inherited debt, $B$ and the contemporaneous realization of $\psi$, but before the agents' idiosyncratic day-shock is realized. Let $\Gamma \in[-1, \bar{B}]$ be the set of possible debt levels, where $\bar{B}$ is large enough so that it does not constraint government behavior. Proposition 1 below shows that the lower bound on $\Gamma$ is not restrictive either.

\footnotetext{
${ }^{6}$ Alternatively, we could assume that this type of financial institutions do not exist and/or that the day market is decentralized and subject to trading frictions. Martin (2011a) shows that all these alternative variants of the Lagos-Wright framework display very similar - both qualitative and quantitative - government policy response to expenditure shocks. The particular variant adopted here has the advantage eliminating the quantitative role of $\eta$ and simplifying some analytics.
} 


\subsection{Monetary equilibrium}

An agent starts the period with-normalized-money balances $m$ and government bonds $b$. The ex-ante value for an agent that enters the day market is $V(m, b, B, \psi)=\eta V^{c}(m, b, B, \psi)+(1-$ $\eta) V^{p}(m, b, B, \psi)$, where $\{B, \psi\}$ is the aggregate state, and $V^{c}$ and $V^{p}$ are the values of being a consumer and a producer in the day market, respectively. Since bonds and bank claims are redeemed in fiat money at par, the composition of an agent's nominal portfolio at the beginning of the night is irrelevant. Note that bank claims at the beginning of the night market may be positive (deposits) or negative (loans) and include the accrued interest. Let $W(z, B, \psi)$ be the value for an agent that starts the night market with $z$ net nominal assets. To simplify exposition, let us omit the dependence of prices and policy variables from aggregate state variables.

The problem of a consumer in the day is

$$
V^{c}(m, b, B, \psi)=\max _{x, l} u(x)+W(m+b-\tilde{p} x-i l, B, \psi) .
$$

subject to $m+l-\tilde{p} x \geq 0$, where $\tilde{p}$ is the normalized price of the day-good. Let $\kappa$ be an individual producer's output of the day-good. The problem of a producer is

$$
V^{p}(m, b, B, \psi)=\max _{\kappa, d}-\phi \kappa+W(m+b+\tilde{p} \kappa+i d, B, \psi)
$$

subject to $m-d \geq 0$. In equilibrium, producers deposit all their money holdings (without loss of generality if $i=0)$. In turn, consumers borrow these funds to supplement their own balances.

The problem of an agent at night is

$$
W(z, B, \psi)=\max _{c, n, m^{\prime}, b^{\prime}} U(c)-\alpha n+\psi v(g)+\beta E\left[V\left(m^{\prime}, b^{\prime}, B^{\prime}, \psi^{\prime}\right) \mid \psi\right] .
$$

subject to $p c+(1+\mu)\left(m^{\prime}+q b^{\prime}\right)=p(1-\tau) n+z$.

The derivation of a monetary equilibrium in this economy is standard, so the details are relegated to Appendix B. A key result in the Lagos-Wright framework is that, in a symmetric equilibrium, all agents exit the night market with the same money and bond balances, i.e., $m^{\prime}=1$ and $b^{\prime}=B^{\prime}$. The resource constraint in the day, $\eta x=(1-\eta) \kappa$ and night, $c+g=n$, can be used to remove $\kappa$ and $n$ from the problem. Equilibrium in the day market implies $d=1, l=\frac{1-\eta}{\eta}, \tilde{p}=\frac{1}{\eta x}$ and $i=\frac{u_{x}}{\phi}-1$.

The literature on optimal policy typically applies what is known as the primal approach, which consists of using the first-order conditions of the agent's problem to substitute prices and policy instruments for allocations in the government budget constraint. Following this approach, the problem of a government with limited commitment can be written in terms of choosing debt and allocations. Given (6) we need to obtain expressions for $\mu, \tau, p$ and $q$. In a monetary equilibrium:

$$
\begin{aligned}
\mu & =\frac{\beta E\left[u_{x}^{\prime} x^{\prime} \mid \psi\right]}{\phi x}-1 \\
\tau & =1-\frac{\alpha}{U_{c}} \\
p & =\frac{U_{c}}{\eta \phi x} \\
q & =\frac{\phi E\left[x^{\prime} \mid \psi\right]}{E\left[u_{x}^{\prime} x^{\prime} \mid \psi\right]} .
\end{aligned}
$$


Additional expressions which are useful for building intuition are the marginal values of money and bonds in equilibrium: $V_{m}=\eta U_{x} x, V_{b}=\eta \phi x$ and $W_{z}=\eta \phi x$.

There is a one more restriction on the equilibrium conditions, $x\left(u_{x}-\phi\right) \geq 0$, which comes from the requirement that the Lagrange multiplier associated with the day-consumer's budget constraint be non-negative. This requirement can also be expressed as $V_{m}-W_{z} \geq 0$, which implies that for money to be valued in equilibrium, it has to provide liquidity services in the day market. Specifically, money allows consumers to buy day-output. Note that since this restriction is satisfied in every period and for all states, it implies from (5) that $q \leq 1$, i.e., the nominal interest rate - defined as $\frac{1}{q}-1$ - cannot be negative in a monetary equilibrium. As shown below, this restrictions does not bind for any $B \in \Gamma, \psi \in \Psi$.

\subsection{Problem of the government}

Using conditions (2)-(5), the government budget constraint (1) becomes

$$
\left(U_{c}-\alpha\right) c-\alpha g+\beta \eta E\left[x^{\prime}\left(u_{x}^{\prime}-\phi\right) \mid \psi\right]+\beta \phi \eta E\left[x^{\prime} \mid \psi\right]\left(1+B^{\prime}\right)-\eta \phi x(1+B)=0 .
$$

Note that $x^{\prime}$ is implemented by the government tomorrow, depending on the inherited level of debt and the realization of the aggregate shock. Thus, let $x^{\prime} \equiv \mathcal{X}\left(B^{\prime}, \psi^{\prime}\right)$, where $\mathcal{X}(B, \psi)$ is the policy that the current government anticipates will be followed in the future.

Although the problem of the government will be written in terms of debt and allocations, there is a correspondence between policy variables and allocations. From (2), for a given $B^{\prime}$ and $x^{\prime} \equiv \mathcal{X}\left(B^{\prime}, \psi^{\prime}\right)$, a higher $\mu$ implies a lower $x$. In other words, given current debt policy and future monetary policy, the allocation of the day-good is a function of current monetary policy. Thus, we can interchangeably refer to variations in the day-good allocation and variations in current monetary policy. Similarly, from (3) a higher tax rate $\tau$ is equivalent to lower night-good consumption, $c$.

Given aggregate state $(B, \psi)$ and anticipating that future governments will implement $\mathcal{X}(B, \psi)$, the problem of the current government is

$$
\mathcal{V}(B, \psi)=\max _{B^{\prime}, x, c, g} \eta(u(x)-\phi x)+U(c)-\alpha(c+g)+\psi v(g)+\beta E\left[\mathcal{V}\left(B^{\prime}, \psi^{\prime}\right) \mid \psi\right]
$$

subject to (6) and $u_{x}-\phi \geq 0 .{ }^{7}$ Government policy in equilibrium is defined as follows.

Definition 1 A Markov-perfect monetary equilibrium is a set of functions $\{\mathcal{B}, \mathcal{X}, \mathcal{C}, \mathcal{G}, \mathcal{V}\}: \Gamma \times \Psi \rightarrow$ $\Gamma \times \mathbb{R}_{+}^{3} \times \mathbb{R}$, such that for all $B \in \Gamma$ and all $\psi \in \Psi$ :

$$
\{\mathcal{B}(B, \psi), \mathcal{X}(B, \psi), \mathcal{C}(B, \psi), \mathcal{G}(B, \psi)\}=\underset{B^{\prime}, x, c, g}{\operatorname{argmax}} \eta(u(x)-\phi x)+U(c)-\alpha(c+g)+\psi v(g)+\beta E\left[\mathcal{V}\left(B^{\prime}, \psi^{\prime}\right) \mid \psi\right]
$$

subject to (6) and $u_{x}-\phi \geq 0$; and

$$
\mathcal{V}(B, \psi)=\eta(u(\mathcal{X}(B, \psi))-\mathcal{X}(B, \psi))+U(\mathcal{C}(B, \psi))-\alpha(\mathcal{C}(B, \psi)+\mathcal{G}(B, \psi))+\psi v(\mathcal{G}(B, \psi))+\beta E\left[\mathcal{V}\left(\mathcal{B}(B, \psi), \psi^{\prime}\right) \mid \psi\right]
$$

\footnotetext{
${ }^{7}$ Note that in the government's objective, we simplify the expected day-utility, $\eta u(x)-(1-\eta) \kappa$ by using the day-market clearing condition, $\eta x=(1-\eta) \kappa$.
} 


\subsection{Characterization}

Assume the policy function $\mathcal{X}(B, \psi)$ followed by future governments is differentiable with respect to debt. ${ }^{8}$ Let $\lambda$ and $\zeta$ be the Lagrange multipliers associated with the government budget and non-negativity constraints, respectively. Using $\mathcal{V}_{B}=\lambda \eta \phi x$, the first-order conditions imply

$$
\begin{aligned}
E\left[\phi x^{\prime}\left(\lambda-\lambda^{\prime}\right)+\lambda \mathcal{X}_{B}^{\prime}\left(u_{x x}^{\prime} x^{\prime}+u_{x}^{\prime}+\phi B^{\prime}\right) \mid \psi\right] & =0 \\
u_{x}-\phi-\lambda \phi(1+B)+\zeta u_{x x} & =0 \\
U_{c}-\alpha+\lambda\left(U_{c}+U_{c c} c-\alpha\right) & =0 \\
-\alpha+\psi v_{g}-\lambda \alpha & =0 .
\end{aligned}
$$

The following statement establishes some important properties of the equilibrium and is an extension of the findings in Martin $(2011 a, b)$ to an economy with aggregate uncertainty. See proof in Appendix C.

Proposition 1 In a $M P M E$, for all $B \in \Gamma, \psi \in \Psi$ : (i) $\lambda>0$; (ii) $\zeta=0$; (iii) $\mathcal{X}_{B}<0$; and (iv) $B^{\prime}>-1$ and $q<1$.

Part (i) states that the government budget constraint always binds. Given the incentives to smooth distortions over time, the government will not implement the first-best allocation in the current period if there are expected distortions in the future. In order to eliminate policy distortions, the government would need to: contract the money supply at the discount rate; impose zero taxes; and provide the state-contingent first-best level of expenditure. In principle, there are two ways it could achieve this. First, the government could start with sufficient claims on the private sector to implement the first-best. The amount of negative debt that is necessary to apply this policy is well outside of $\Gamma$. A second possibility is that the government implements the first-best allocation by continually rolling over the debt. This policy is inconsistent with equilibrium, as shown in the proof - see Appendix C. Given $\lambda>0$ it follows, from (3) and (9), that $\tau>0$, i.e., tax rates are always positive, for all levels of debt and all expenditure states. Similarly, from (10) the public good provision is always below the efficient level.

Proposition 1(ii) verifies that the non-negativity constraint $u_{x}-\phi \geq 0$ does not bind and hence, can be omitted from the characterization of the government's problem.

Proposition 1(iii) rules out the possibility that the day-good allocation could be (weakly) increasing in debt. This would be inconsistent with an equilibrium since it would imply the government could increase debt and welfare at the same time, which in turn would mean it is not constrained by a budgetary restriction. Except at $B=-1$, the day-good allocation is always inefficient: for all $\psi \in \Psi, \mathcal{X}(-1, \psi)=\hat{x}$ and $\mathcal{X}(B, \psi)<\hat{x}$ for all $B>-1$.

Finally, Proposition 1 (iv) offers two important results. First, $1+\mathcal{B}(B, \psi)>0$, which means the government always chooses to carry-over strictly positive net nominal liabilities (money plus bonds). Second, the Friedman rule of zero nominal interest rate $(q=1)$ is not implemented in equilibrium, for any level of debt and any expenditure state.

\footnotetext{
${ }^{8}$ This is a refinement that rules out equilibria where discontinuities in policy are not rooted in the environment fundamentals, but are rather an artifact of the infinite horizon. For an analysis and discussion of non-differentiable Markov-perfect equilibria see Krusell and Smith (2003) and Martin (2009). See also Martin (2011b) for further discussion in a similar context.
} 


\subsection{Determination of government policy}

The derivative of the equilibrium function $\mathcal{X}(B, \psi)$ in the government's first-order condition (7), reflects a time-consistency problem, as the government tomorrow will not internalize how its policy affected current actions. In equilibrium, government policy results from the interaction between monetary policy and government debt. This interaction introduces both intratemporal and intertemporal trade-offs.

First, the government has an incentive to inflate away its nominal liabilities, at the cost of distorting the allocation of the day-good. From (8), given $1+B \geq 0$, an increase in beginning-ofperiod debt, $B$, implies a decrease in day-good consumption, $x$. In other words, the incentive to use inflation increases with the level of debt and thus, $\mathcal{X}_{B}<0$. This is the channel through which debt affects monetary policy.

Second, the government faces an intertemporal trade-off, as stated in (7). The term $E\left[\phi x^{\prime}(\lambda-\right.$ $\left.\left.\lambda^{\prime}\right) \mid \psi\right]$ is the standard trade-off between current and future distortions, and is the basis for the classic tax-smoothing argument. The government's limited commitment introduces an additional term, $\lambda E\left[\mathcal{X}_{B}^{\prime}\left(u_{x}^{\prime}+u_{x x}^{\prime} x^{\prime}+\phi B^{\prime}\right) \mid \psi\right]$. To better understand this term notice that $\frac{d V_{m}^{\prime}}{d x^{\prime}}=\eta\left(u_{x x}^{\prime} x^{\prime}+u_{x}^{\prime}\right)$ and $\frac{d V_{b}^{\prime}}{d x^{\prime}}=\eta \phi$. Thus, given $\lambda>0$, the sign of the second term in (7) is equal to the sign of

$$
E\left[\frac{d V_{m}^{\prime}}{d x^{\prime}} \mathcal{X}_{B}^{\prime} \mid \psi\right]+E\left[\frac{d V_{b}^{\prime}}{d x^{\prime}} \mathcal{X}_{B}^{\prime} \mid \psi\right] B^{\prime}
$$

For the sake of the argument, suppose $u(x)$ is such that $u_{x x} x+u_{x}<0$ for all $x>0$, which implies $\frac{d V_{m}^{\prime}}{d x^{\prime}} \mathcal{X}_{B}^{\prime}>0$. This means that if the government increases the debt today, there is an increase in tomorrow's marginal value of money. I.e., agents tomorrow, facing higher inflation due to higher debt, would have preferred to have arrived with more money. Thus, the current demand for money increases, which relaxes the government budget constraint. On the other hand, $\frac{d V_{b}^{\prime}}{d x^{\prime}} \mathcal{X}_{B}^{\prime}<0$ since increasing the debt today implies higher future inflation, which reduces the current demand for bonds. In other words, the interest rate paid on debt increases, which tightens the government budget constraint. For low levels of debt, the former effect dominates, providing an incentive to increase the debt, whereas for large levels of debt the latter effect dominates, providing an incentive to decrease debt. The gains from these incentives are offset by the losses due to lower intertemporal distortion smoothing, i.e., a larger wedge $\lambda-\lambda^{\prime}$.

From (10) we get $\lambda=\frac{\psi v_{g}}{\alpha}-1$ and thus,

$$
\begin{aligned}
E\left[\phi x^{\prime}\left(\psi v_{g}-\psi^{\prime} v_{g}^{\prime}\right)+\left(\psi v_{g}-\alpha\right) \mathcal{X}_{B}^{\prime}\left(u_{x}^{\prime}+u_{x x}^{\prime} x^{\prime}+\phi B^{\prime}\right) \mid \psi\right] & =0 \\
\alpha\left(u_{x}-\phi\right)-\left(\psi v_{g}-\alpha\right) \phi(1+B) & =0 \\
\psi v_{g}\left(U_{c}-\alpha\right)+\left(\psi v_{g}-\alpha\right) U_{c c} c & =0 .
\end{aligned}
$$

Definition 2 A MPME is characterized by a set of functions $\{\mathcal{B}(B, \psi), \mathcal{X}(B, \psi), \mathcal{C}(B, \psi), \mathcal{G}(B, \psi)\}$ : $\Gamma \times \Psi \rightarrow \Gamma \times \mathbb{R}_{+}^{3}$ that solve (6), (11), (12) and (13) for all $B \in \Gamma$ and $\psi \in \Psi$. 


\section{Numerical Evaluation}

This section evaluates how the theoretical model presented above helps explain the qualitative and quantitative facts of U.S. wartime policy, as described in Section 2. The analysis proceeds in several steps. First, the model is calibrated to match long-run averages of the post-war U.S. economy. Second, the model is simulated with war episodes to evaluate the qualitative and quantitative facts previously described. Third, the calibration is modified slightly to account for the pre-World War II state of the economy and a World War II-like episode is simulated. The simulated model is then compared with the actual behavior of U.S. policy during World War II. Finally, the model is used to interpret the atypical policy implemented in response to the Korean War.

\subsection{Calibration}

Consider the following functional forms:

$$
\begin{aligned}
u(x) & =\frac{x^{1-\sigma}-1}{1-\sigma} \\
U(c) & =\frac{c^{1-\rho}-1}{1-\rho} \\
v(g) & =\ln g .
\end{aligned}
$$

This preference specification implies that both the money growth rate and tax revenue over GDP are increasing in debt, whereas expenditure over GDP is relatively flat - see Figure 5 in Appendix D. It follows that the primary deficit (expenditure minus tax revenue) is decreasing in debt, which is a feature of the U.S. data, as documented by Bohn (1998). A decreasing primary deficit justifies separable preferences in day and night goods, which is a natural assumption in the Lagos-Wright framework. ${ }^{9}$

The approach follows Martin (2011a), which calibrates several variants of the Lagos-Wright framework. That paper shows that the model and calibration adopted here does a good job at replicating the time-series properties of policy variables in post-war U.S., when including both expenditure and productivity shocks. In addition, the model can account for non-targeted properties of the data, such as the persistence of policy variables, the money demand function (i.e., the relationship between the nominal interest rate and velocity of circulation) and the Phillips curve (i.e., the relationship between output and inflation). ${ }^{10} \mathrm{~A}$ relevant result is that, when only considering expenditure shocks, as we do here, it does not matter whether we abstract from financial institutions or consider trading frictions. Performance differences across model variants stem from the response to productivity shocks.

\footnotetext{
${ }^{9}$ Indeed, as shown in Martin (2009) in the context of a cash-credit good model, if we assume non-separable utility between the two private goods, then these need to be (strong) complements to match observed debt over GDP. However, this implies tax revenue is decreasing in debt and thus, primary deficit is increasing rather than decreasing in debt. A related outcome is a steep money growth rate function (since revenue increases with debt, inflation is needed to finance the higher financial burden), which implies unrealistically high inflation in response to expenditure shocks.

${ }^{10}$ If we run money demand and Phillips curve regressions using the simulated data described in the following section, the estimated relationships between variables remain close to the data. Details are available upon request.
} 
Target statistics are taken from 1962-2006 averages for the U.S. economy. Period length is set to a year. Government in the model corresponds to the federal government. The calibration targets are: debt over GDP, annual inflation, interest payment over GDP, outlays (excluding interest) over GDP and revenues over GDP. Inflation is measured from the CPI, while the rest of the variables are taken from the Congressional Budget Office. Government debt is defined as debt held by the public, excluding holdings by the Federal Reserve system.

In the model, target statistics are derived from the non-stochastic steady state. Since $\mathcal{X}_{B}<0$ from Proposition 1, if $\psi$ is constant then (11) becomes $u_{x}^{*}+u_{x x}^{*} x^{*}+\phi B^{*}=0$. Given the adopted functional forms, we obtain

$$
B^{*}=\frac{\sigma-1}{\phi x^{* \sigma}} .
$$

A steady state is an allocation $\left\{B^{*}, x^{*}, c^{*}, g^{*}\right\}$ satisfying (6), (12), (13) and (14), given a constant value for $\psi$.

For debt over GDP use $\frac{B^{*}\left(1+\mu^{*}\right)}{Y^{*}}$, where $Y^{*}$ is steady state nominal GDP normalized by the aggregate money stock (and equal to velocity of circulation by the "equation of exchange"); note the use of $B^{*}\left(1+\mu^{*}\right)$ instead of just $B^{*}$ since debt is measured at the end of the period in the data. We have $Y^{*}=\eta \tilde{p}^{*} x^{*}+p^{*}\left(c^{*}+g^{*}\right)=1+p^{*}\left(c^{*}+g^{*}\right)$. Let $\pi^{*}$ be steady state annual inflation, which is equal to $\mu^{*}$. Interest payments over GDP are defined as $\frac{B^{*}\left(1+\mu^{*}\right)\left(1-q^{*}\right)}{Y^{*}}$. Given that debt over GDP is already targeted, this implies a target for the nominal interest rate $i^{*}$, where $i^{*}=\frac{1}{q^{*}}-1$. Interest payments are 2.1\% of GDP in the data, which implies a target nominal interest rate of $7.3 \%$ annual. Outlays and revenues are defined as $\frac{p^{*} g^{*}}{Y^{*}}$ and $\frac{p^{*} \tau^{*}\left(c^{*}+g^{*}\right)}{Y^{*}}$, respectively. Table 2 displays the target statistics. ${ }^{11}$

Table 2: Target statistics

\begin{tabular}{|c|c|c|c|c|}
\hline$\frac{B^{*}\left(1+\mu^{*}\right)}{Y^{*}}$ & $\pi^{*}$ & $i^{*}$ & $\frac{p^{*} \tau^{*}\left(c^{*}+g^{*}\right)}{Y^{*}}$ & $\frac{p^{*} g^{*}}{Y^{*}}$ \\
\hline 0.308 & 0.044 & 0.073 & 0.182 & 0.182 \\
\hline
\end{tabular}

Table 3 displays the parameters that match the calibration targets. The values for $\psi$ is normalized to 1 and the value of $\eta$ is set arbitrarily to 0.5 . This leaves 5 parameters for 5 calibration targets. Appendix E shows that expanding the number of parameters available for calibration does not alter the results in any significant way.

\subsection{Policy response to wars}

This section evaluates the response of government policy to war-expenditure shocks. In order to solve the model numerically, let us discretize the expenditure state. Let $\Psi=\left\{\psi_{1}, \ldots, \psi_{N}\right\}$

\footnotetext{
${ }^{11}$ Note that due to the presence of financial intermediaries, the relative size of the day-market is larger than in calibrations without banks. For example, adopting a similar calibration approach in an environment without financial intermediaries implies output in the day-market is $9 \%$ of total GDP, which is standard. Here, this fraction is $18 \%$. The difference comes from the fact that the demand for goods in the day-market is larger when there is financial intermediation, since money held by producers is not sitting idly and is instead being borrowed by consumers to purchase day-goods. As mentioned above, abstracting from financial intermediaries does not alter the policy response of the government to expenditure shocks. See Martin (2011a) for further analysis.
} 
Table 3: Benchmark calibration

\begin{tabular}{|c|c|c|c|c|}
\hline$\alpha$ & $\beta$ & $\rho$ & $\sigma$ & $\phi$ \\
\hline 4.1722 & 0.9728 & 8.1879 & 2.5084 & 4.8290 \\
\hline \multicolumn{5}{c|}{ Note: $\psi=1.0$ and $\eta=0.5}$.
\end{tabular}

for $N \geq 2,0<\psi_{1}<\ldots<\psi_{N}$, and let $\Pi\left(\psi_{i} \mid \psi_{j}\right)=\operatorname{Prob}\left(\psi^{\prime}=\psi_{i} \mid \psi=\psi_{j}\right)$. The model is solved globally, using the method described in Appendix D. The numerical approximation provides equilibrium functions $\left\{\mathcal{B}^{i}(B), \mathcal{X}^{i}(B), \mathcal{C}^{i}(B), \mathcal{G}^{i}(B)\right\}_{i=1}^{N}$, from which the state-contingent policy variables can be constructed.

The conditional probabilities of war and peace are problematic to measure since we only observe realized outcomes in a small sample. One way to proceed is to take the frequency and duration of wars in the data, and use this information to construct the transition matrix. I take the values used in Martin (2009), which imply an unconditional probability of $9 \%$ for war, with an average duration of 4.5 years. Consistent with these targets, let $\mathcal{P}=0.9775$ be the probability of remaining in peacetime next period and $\mathcal{W}=0.7778$ the probability that a current war continues next period. In the exercises that follow, I will restrict myself to only using these two parameters when constructing transition matrices.

Since the economy was calibrated to the period 1962-2006, with public expenditure at $18 \%$ of GDP, it seems appropriate to use the levels of expenditure observed during World War II to simulate war episodes. Consider two alternative simulations. First, an economy with only two states, "peace" and "war". Thus, let $\Psi=\left\{\psi_{L}=1, \psi_{H}=2\right\}$, which implies wartime expenditure of about $31 \%$ of GDP, roughly the average during War World II. The transition probabilities consistent with the targets mentioned above are: $\Pi\left(\psi_{L} \mid \psi_{L}\right)=\mathcal{P} ; \Pi\left(\psi_{H} \mid \psi_{L}\right)=1-\mathcal{P} ; \Pi\left(\psi_{H} \mid \psi_{H}\right)=\mathcal{W}$; and $\Pi\left(\psi_{L} \mid \psi_{H}\right)=1-\mathcal{W}$.

Second, suppose expenditure increases gradually, rather than abruptly, which is a more realistic depiction of war episodes. For example, during World War II, federal outlays over GDP first climbed from an average of $8 \%$ to about $21 \%$ in 1942, then stayed at roughly $40 \%$ for three years, came down to $23 \%$ in 1946 and finally settled around $12 \%$ until the start of the Korean War. To match this behavior, let $\Psi=\left\{\psi_{L}=1, \psi_{M}=1.25, \psi_{H}=3\right\}$. This parameterization implies wartime expenditure of about $22 \%$ and $40 \%$ of GDP, depending on the state. Treating the two warexpenditure states symmetrically implies the following transition probabilities: $\Pi\left(\psi_{L} \mid \psi_{L}\right)=\mathcal{P}$; $\Pi\left(\psi_{M} \mid \psi_{L}\right)=\Pi\left(\psi_{H} \mid \psi_{L}\right)=(1-\mathcal{P}) / 2 ; \Pi\left(\psi_{M}, \psi_{M}\right)=\Pi\left(\psi_{H}, \psi_{H}\right)=\Pi\left(\psi_{H} \mid \psi_{M}\right)=\Pi\left(\psi_{M} \mid \psi_{H}\right)=$ $\mathcal{W} / 2$; and $\Pi\left(\psi_{L} \mid \psi_{M}\right)=\Pi\left(\psi_{L} \mid \psi_{H}\right)=1-\mathcal{W}$.

Let us first focus on the qualitative response of policy to a war expenditure shock. Figure 2 shows the simulated policy response to a 5-period war, for both cases described above. The economy is assumed to be in the low expenditure state (peacetime) for 100 periods, after having started at the non-stochastic steady state, $B^{*}$. In period " 1 " the economy is hit by a war shock which lasts for 5 periods (like World War II) and then goes back to peacetime for the remaining periods. For the two-state case, we have $\psi_{H}$ from periods " 1 " to " 5 "; for the three state case, we have $\psi_{M}$ for periods "1" and "5", and $\psi_{H}$ for periods "2", "3" and "4". The series for real GDP is normalized by the corresponding long-run value during peacetime, so that it is equal to zero right 
before the war shock is realized.

In the periods leading up to the war shock, debt over GDP and inflation are considerably lower than in the calibrated non-stochastic steady state. The reason for this is that, in the stochastic economy, the government has less incentives to build up debt during peacetime since it expects to issue a significant amount during wartime. ${ }^{12}$ In other words, the lower peacetime debt-relative to an economy with no uncertainty - is a direct consequence of distortion smoothing. The lower inflation is related to the lower debt, since there is less to service.

As we can see in Figure 2, the model qualitatively matches all the five stylized facts enumerated in Section 2, regardless of whether we use two or three expenditure states. First, the government uses a mix of contemporaneous instruments to finance the war. Second, the increase in debt is large and persistent, more so than any other policy variable. These two results extend the findings in Martin (2009) to the Lagos-Wright framework. Third, there is a significant increase in the primary deficit, followed by a persistent post-war surplus. As in the data, tax revenue remains higher than pre-war levels for a longer period than expenditure. Fourth, inflation increases during wartime to finance expenditure and in the post-war period helps reduce the burden of accumulated debt. Fifth, there is a significant increase in real GDP during the war.

Although the money growth rate is single-peaked, inflation is saw-shaped. Specifically, both simulated inflation series register a sharp dip in the first post-war year. What happens is that, as the economy reverts back to peacetime expenditure levels, the lower money growth and tax rates imply an increase in private (day and night) consumption. These effects significantly increase the demand for money, which puts a temporary brake on inflation. Immediately after, inflation goes back up since the demand for money is relatively stabilized, while the money growth rate is still above pre-war levels.

The two simulation approaches - sudden and gradual - differ significantly in the quantitative response of policy. Recall that average wartime expenditure is the same in both cases; the difference is in how the burden is distributed over time. Figure 2 shows that when the increase in expenditure is gradual, tax revenue, debt and inflation all increase considerably more. Similarly, the response of the primary deficit and GDP is more pronounced in the three expenditure-states case. Note also that the initial policy response in the gradual case is tamer. These results follow from standard tax-smoothing arguments. In the gradual case, when the economy initially goes to the medium expenditure state, the policy response is moderated by the fact that even higher expenditure is very likely in the immediate future. When the economy arrives at the high expenditure state, the government relies more heavily on deficit financing, to better smooth distortions over time. Compared to the sudden case, the highest expenditure level in the gradual case is expected to be of shorter duration, which motivates the more dramatic response.

The performance of the model is a significant improvement over Martin (2009). Compared to the World War II-type shock analyzed in that paper, the behavior of inflation and tax revenue is more empirically plausible here. First, inflation does not climb to implausibly high numbers; second, revenue does not exhibit a sharp post-war slump. In addition, the exercise here addresses the behavior of the primary deficit and output.

Table 4 compares the quantitative performance of the two artificial economies. Each is simulated

\footnotetext{
${ }^{12}$ This result is quite general. E.g., see Lucas (1986).
} 
Figure 2: Simulated government response to a war shock
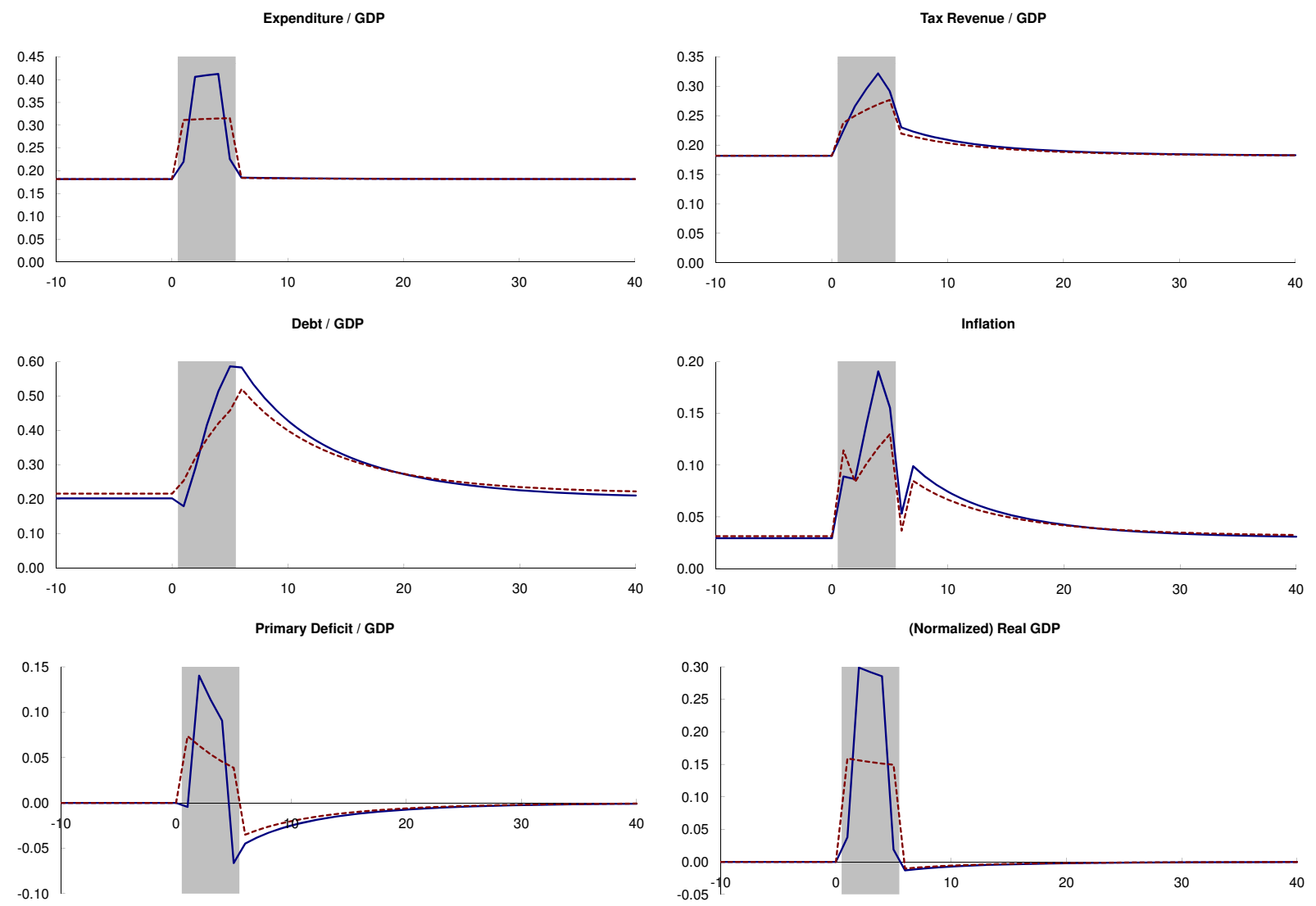

Note: Dashed and solid lines correspond to the calibrations with two and three expenditure states, respectively. Periods with wartime expenditure are highlighted.

for 10,000,000 periods. The table compares peak value relative to pre-war average, for selected variables. The first column in Table 4 summarizes the observed behavior in the three war episodes considered, as reported in Table 1. The second and third columns report averages and standard deviations for the two simulations. Note that for the artificial economies, the table reports war episodes that last for at least 2 years and that were preceded by at least 10 years of peace. This is done to get measures that are comparable to the data. If we were to only include wars that last for 3 years, then the only average that changes significantly is the one reported for debt over GDP, since debt growth is directly tied to the actual duration of a war.

Both simulated economies display statistics within the ranges observed in the data. The economy with two expenditure states appears to slightly under-predict wartime deficit and inflation, whereas the three state economy conforms with the observed range for all variables. In both cases we can obtain larger responses in debt by filtering out wars of shorter duration. In all, Table 4 shows that the simulations and corresponding policy responses analyzed here are empirically plausible. 
Table 4: War peak vs 5-year pre-war average - data and simulated models

\begin{tabular}{|l|c|c|c|}
\hline & U.S. Wars & $\begin{array}{c}\text { Model w/ } \\
\text { 2 States }\end{array}$ & $\begin{array}{c}\text { Model w/ } \\
\text { 3 States }\end{array}$ \\
\hline Outlays/GDP & 0.213 & 0.133 & 0.211 \\
& $(0.107)$ & $(0.002)$ & $(0.055)$ \\
Revenue/GDP & 0.081 & 0.090 & 0.115 \\
& $(0.047)$ & $(0.018)$ & $(0.038)$ \\
Deficit/GDP & 0.166 & 0.074 & 0.128 \\
& $(0.083)$ & $(0.001)$ & $(0.040)$ \\
Debt/GDP & 0.388 & 0.267 & 0.300 \\
Inflation & $(0.165)$ & $(0.094)$ & $(0.173)$ \\
& 0.166 & 0.095 & 0.128 \\
GDP & $(0.067)$ & $(0.025)$ & $(0.057)$ \\
& 0.179 & 0.159 & 0.275 \\
& $(0.171)$ & $(0.000)$ & $(0.075)$ \\
\hline
\end{tabular}

Note: For each variable, the table displays peak value during wartime minus the average of the 5 preceding years. The wartime period includes the year following the end of the war, to capture variables that may peak with a lag. The column "U.S. Wars" averages the information displayed in Table 1. The figures for GDP include the series detrended with a quadratic polynomial and with an HP-filter with smoothing parameter equal to 100. Artificial economies are run for 10,000,000 periods. Reported averages for the model correspond to war episodes that last at least 2 years and were preceded by at least 10 years of "peace". Numbers in parenthesis are standard deviations.

\subsection{World War II simulation}

This section takes the quantitative evaluation of the model one step further by considering its fit to a specific war-episode, World War II. Expenditure before the war and immediately after was significantly lower than in the calibrated peacetime. To properly account for these lower levels without altering the benchmark calibration, let us increase the number of expenditure states to four. Let $\Psi=\left\{\psi_{0}=0.5, \psi_{L}=1, \psi_{M}=1.25, \psi_{H}=3\right\}$, where $\psi_{0}$ targets an expenditure level of about $10 \%$ of GDP. This level is an average of the 5 years preceding the war $(8 \%)$ and the 5 years following the war (12\%), and also happens to be the level in 1941, right before defense expenditure for World War II began.

I continue using the same two basic parameters, $\mathcal{P}$ and $\mathcal{W}$. The only issue now is how to assign them across the transition matrix. I assume the following. If the economy is in $\psi_{0}$, then going to $\psi_{L}$ will be as likely as going to any war-expenditure level. Once in $\psi_{L}$, the expenditure state is perceived as the new "peace" level, and going back to $\psi_{0}$ is as likely as going to any of the war states. If in a war, then going back to $\psi_{0}$ is perceived to be as likely as continuing to be at war, whereas going to $\psi_{L}$ represents the perceived persistent peacetime expenditure level. The corresponding probabilities are then: $\Pi\left(\psi_{0} \mid \psi_{0}\right)=\Pi\left(\psi_{L} \mid \psi_{L}\right)=\mathcal{P}$; $\Pi\left(\psi_{L} \mid \psi_{0}\right)=\Pi\left(\psi_{M} \mid \psi_{0}\right)=\Pi\left(\psi_{H} \mid \psi_{0}\right)=$ $\Pi\left(\psi_{0} \mid \psi_{L}\right)=\Pi\left(\psi_{M} \mid \psi_{L}\right)=\Pi\left(\psi_{H} \mid \psi_{L}\right)=(1-\mathcal{P}) / 3 ; \Pi\left(\psi_{M}, \psi_{M}\right)=\Pi\left(\psi_{H}, \psi_{H}\right)=\Pi\left(\psi_{0} \mid \psi_{M}\right)=$ $\Pi\left(\psi_{H} \mid \psi_{M}\right)=\Pi\left(\psi_{0} \mid \psi_{H}\right)=\Pi\left(\psi_{M} \mid \psi_{H}\right)=\mathcal{W} / 3 ;$ and $\Pi\left(\psi_{L} \mid \psi_{M}\right)=\Pi\left(\psi_{L} \mid \psi_{H}\right)=1-\mathcal{W}$.

The model is solved again, as described in Appendix D. The exercise now is to feed a sequence of expenditure states that follow the data from 1940 to 1960. Note that this period includes the 
Figure 3: Simulated government response to World-War II
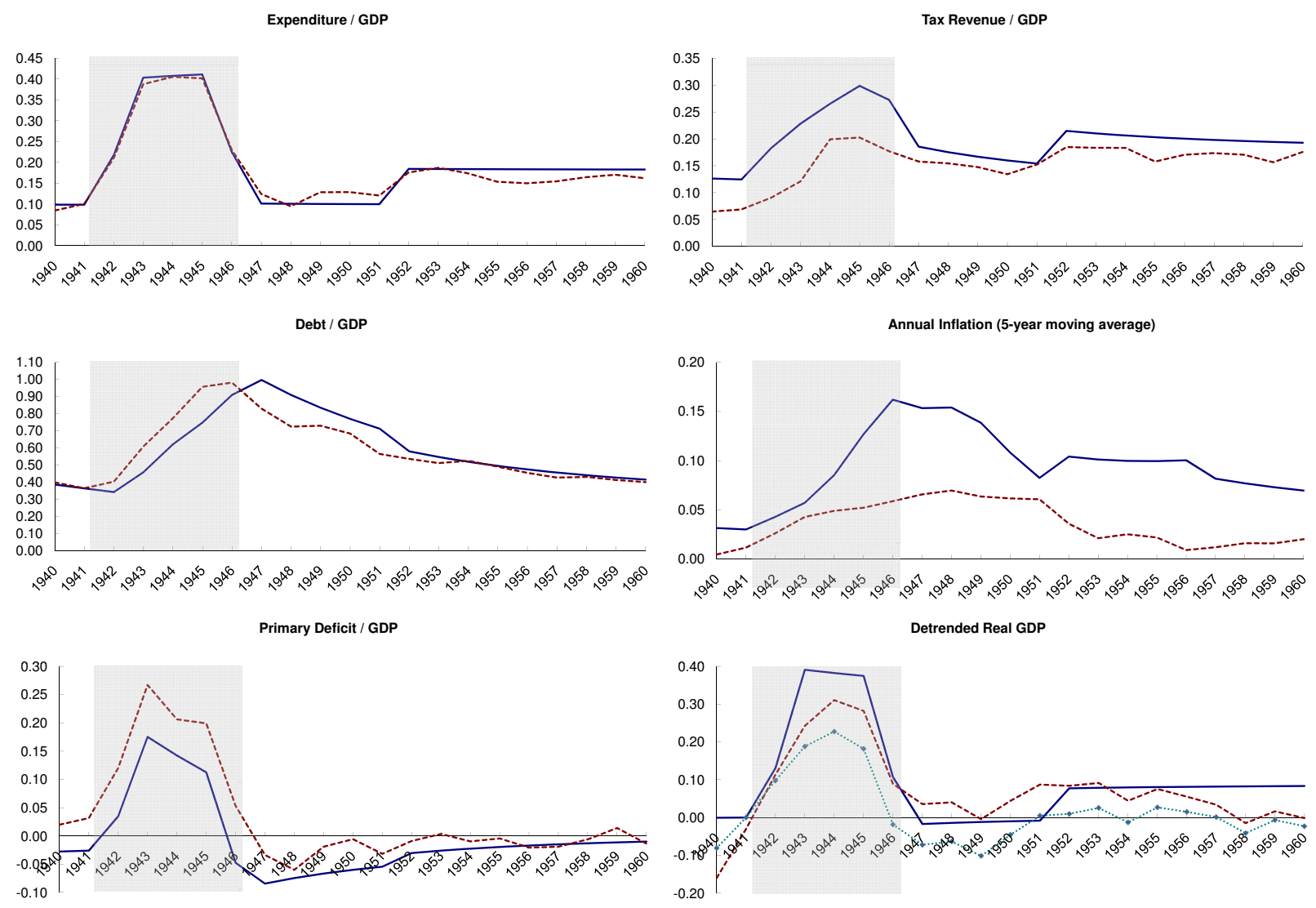

Note: Dashed and solid lines correspond to the data and model, respectively. Years with increased defense expenditure due to World War II are highlighted. Real GDP per capita in the data is detrended using a quadratic polynomial (dashed line) and an HP-filter with a smoothing parameter of 100 (doted line with diamond markers).

subsequent Korean War, which is discussed in the next section. Initial debt in the simulated prewar economy is set so that it converges to the data in 1941, right before the expenditure shock hits.

Figure 3 displays the response of select policy variables to the increase in expenditure during World War II. The dashed lines correspond to the data and the solid lines to the simulated model. Table 5 offers an alternative way of evaluating the model quantitatively, by comparing the wartime peak with the pre-war average.

As we can see, except for inflation, the model accounts well for the policy response in this period, both qualitatively and quantitatively. The government in the model relies more on contemporaneous tax revenue than in the data. This results in a slower pace of debt accumulation and a lower primary deficit. On closer inspection, these differences correspond to a higher real interest rate in the model during wartime. ${ }^{13}$ Notably, though, the repayment of debt in the model occurs at a rate very

\footnotetext{
${ }^{13}$ I thank Marco Bassetto for making this observation.
} 
Table 5: World War II peak vs 5-year pre-war average

\begin{tabular}{|l|c|c|}
\hline & Data & Model \\
\hline Outlays/GDP & 0.322 & 0.313 \\
Revenue/GDP & 0.135 & 0.171 \\
Deficit/GDP & 0.252 & 0.205 \\
Debt/GDP & 0.579 & 0.585 \\
Inflation & 0.132 & 0.204 \\
GDP & 0.382 & 0.392 \\
\hline
\end{tabular}

Note: For each variable, the table displays peak value during wartime minus the average of the 5 preceding years. The wartime period includes the year following the end of the war, to capture variables that may peak with a lag. GDP in the data averages the series detrended with a quadratic polynomial and with an HP-filter with smoothing parameter equal to 100.

similar to the data. This last result confirms earlier findings that models of government policy with limited commitment accounts quite well for the observed persistence in debt-see Martin (2009) and Martin (2011a).

Regarding the response of inflation, we should not expect any stylized model of policy to perform well. During World War II, the government imposed rationing and price controls, aimed at preventing inflation. In fact, even though the model displays higher inflation than the data, monetary aggregates - such as $M_{0}$ and $M_{1}$ - grew significantly more in the data than in the model, albeit with less persistence. Notably, though, the velocity of circulation (nominal output divided by the money stock) exhibits very different behavior in the model and the data. In the model, the large increase in output during wartime mechanically results in an increased velocity of circulation. This is a feature of the underlying monetary economy and not of the specific theory of government policy. In contrast, velocity of circulation in the data shows a decrease during World War II-quite large in the case of $M_{0}$ and more modest in the case of $M_{1}$.

Still, even accounting for repressed inflation and measurement issues during wartime, it does appear that the model would over-predict the (permanent) rise in prices due to a war. For example, consider the increase in prices from 1941 up to 1947, i.e., between the year before and a year after the period with high defense expenditure. The annual inflation rate was $7.2 \%$ if we use the CPI and $9.3 \%$ if we use PPI (as many of the empirical studies cited here have done). The model reports an annual inflation rate of $14.3 \%$, which is significantly higher than either measure- see Table 6 .

Table 6: Inflation during World War II-annualized rates

\begin{tabular}{|c|c|c|c|}
\hline & CPI & PPI & Model \\
\hline $1941-1945$ & 0.052 & 0.050 & 0.151 \\
$1941-1947$ & 0.072 & 0.093 & 0.143 \\
\hline
\end{tabular}

Finally, both in the data and the model, output increases substantially during wartime and returns to trend immediately afterward. For GDP in the data, Figure 3 shows two series: one detrended with a quadratic polynomial and the other using an HP filter. Table 5 shows that the 
model is consistent with the average of these two estimates. Table 7 displays the GDP growth rate between 1941 and 1945. The model reports 9.8\% annual growth on average, which is in between the figures obtained from the data without detrending (10.3\%) and detrending with a quadratic polynomial (8.1\%). As a reference, Ohanian (1997) reports an average annual rate of $9.6 \%$ for GNP over the same period. The growth rate using the HP filter is significantly lower, due to the fact that the filter interprets the Great Depression as a variation in the trend and picks-up the growth during War World II as part of the upswing that started a few years earlier.

Table 7: Real GDP per capita growth 1941-1945-annualized rates

\begin{tabular}{|c|c|c|c|}
\hline \multicolumn{3}{|c|}{ Detrending method } & \multirow{2}{*}{ Model } \\
\cline { 1 - 3 } None & Quadratic & HP-filter & \\
\hline 0.103 & 0.081 & 0.046 & 0.098 \\
\hline
\end{tabular}

\subsection{The Korean War}

As explained by Ohanian (1997) and displayed in Figure 1, the Korean War presents a notable exception to U.S. wartime financing. Specifically, the war was almost exclusively financed with contemporaneous taxes. Ohanian argues that the transitory component of expenditure during the Korean War was significant - both expenditure and tax revenue temporarily rise - and points to President Truman's insistence on a balanced budget policy as a departure from standard taxsmoothing policy.

The simulated sequence of government expenditure levels, as displayed in Figure 3, includes the increased government expenditure state that started in 1951. Although it is true that government expenditure fell immediately after the Korean War, two important observations are in order. First, the fall-back level of expenditure was significantly higher than before the Korean War-about $12 \%$ of GDP between 1947 and 1951 vs a bit over 15\% between 1955 and 1957. Second, starting in 1958, expenditure hovered between $16 \%$ and $17 \%$ of GDP, much closer to the average expenditure during the Korean War (almost 18\%) than to the pre-war level.

Under the assumption that, starting with the Korean War, the economy is at a new persistent expenditure state $\left(\psi_{L}=1\right.$ instead of $\left.\psi_{0}=0.5\right)$, the model correctly predicts this episode's peculiar financing. As we can see, tax revenue increases and debt continues to decrease. There is a persistent primary surplus, as in the data. The only notable difference is the timing of a spike in inflation, which in the model occurs one year after the data. ${ }^{14}$

Following the initial increase in taxes to finance the increase in expenditure, revenue decreases slowly, both in the data and the model. In contrast to Ohanian (1997), who views this reduction as evidence for a temporary component in expenditure during the Korean War, the model explains the behavior in revenue from the ongoing reduction of the financial burden, as debt accumulated during World War II is progressively repaid.

The lesson from this exercise is that the financing of the Korean War is consistent with a tax-

\footnotetext{
${ }^{14}$ This is not visible in Figure 3 since it displays the 5-year moving average of inflation.
} 
smoothing model (with limited commitment), as long as we assume that the increase in government expenditure was perceived as permanent, rather than transitory. The subsequent history of the U.S., which has expenditure climbing to an average of $18 \%$ of GDP, due to new defense and social programs, would conform to this perception.

\section{Concluding remarks}

This paper is a joint test of several working hypothesis for the determination of government policy: distortion-smoothing; limited commitment; government benevolence; and micro-foundations for the role of money. It would be interesting to further understand which of these are not necessary to explain policy during wartime. For example, the degree of government benevolence will probably not affect the results significantly, as long as the government is still assumed to care about smoothing distortions intertemporally and lack the ability to fully commit.

A general lesson from this exercise is that debt accumulation, due to temporary increases in government expenditure, provides strong incentives for higher inflation. This mechanism has a well articulated theoretical foundation and is empirically relevant, as evidenced by the war episodes studied in this paper. The economic and political circumstances of recent years have lead to large increases in debt and the primary deficit. Although core inflation in the U.S. has hovered around the implicit target of $2 \%$ annual and market-based inflation expectations have remained low, there is an ongoing debate about future inflation. Some discussions have focused on whether the policies implemented by the Federal Reserve will eventually translate into higher prices or not. Little attention appears to have been placed on the growing incentives to inflate provided by an increased stock of debt. The results in this paper suggest that we should not dismiss such concerns. 


\section{References}

Aiyagari, S. R., Marcet, A., Sargent, T. J. and Seppälä, J. (2002), 'Optimal taxation without state-contingent debt', The Journal of Political Economy 110(6), 1220-1254.

Aruoba, S. B. and Chugh, S. K. (2010), 'Optimal fiscal and monetary policy when money is essential', Journal of Economic Theory 145(5), 1618-1647.

Balke, N. S. and Gordon, R. J. (1986), Appendix B: Historical data, in 'The American Business Cycle', Chicago: University of Chicago Press.

Barro, R. J. (1979), 'On the determination of the public debt', The Journal of Political Economy 87(5), 940-971.

Berentsen, A., Camera, G. and Waller, C. (2007), 'Money, credit and banking', Journal of Economic Theory 135, 171-195.

Berentsen, A. and Waller, C. (2008), 'Outside versus inside bonds', Working Paper No. 372, Institute for Empirical Research in Economics, University of Zurich .

Bohn, H. (1998), 'The behavior of U.S. public debt and deficits', The Quarterly Journal of Economics 113(2), 949-963.

Chari, V. V., Christiano, L. J. and Kehoe, P. J. (1991), 'Optimal fiscal and monetary policy: Some recent results', Journal of Money, Credit and Banking 23(3), 519-539.

Goldin, C. (1980), War, in G. Porter, ed., 'Encyclopedia of American economic history', New York: Random House, pp. 935-957.

Johnston, L. D. and Williamson, S. H. (2008), 'What was the U.S. GDP then?', MeasuringWorth.com .

Kocherlakota, N. (1998), 'Money is memory', Journal of Economic Theory 81, 232-251.

Krusell, P. and Smith, A. (2003), 'Consumption-savings decisions with quasi-geometric discounting', Econometrica 71(1), 365-375.

Lagos, R. and Wright, R. (2005), 'A unified framework for monetary theory and policy analysis', The Journal of Political Economy 113(3), 463-484.

Lindert, P. H. and Sutch, R. (2006), Consumer price indexes, for all items: 17742003, in S. B. Carter, S. S. Gartner, M. R. Haines, A. L. Olmstead, R. Sutch and G. Wright, eds, 'Historical Statistics of the United States, Earliest Times to the Present: Millennial Edition', New York: Cambridge University Press.

Lucas, R. E. (1976), Econometric policy evaluation: A critique, in K. Brunner and A. Meltzer, eds, 'The Phillips Curve and Labor Markets', Vol. 1, Carnegie-Rochester Conference Series on Public Policy, pp. 19-46.

Lucas, R. E. (1986), 'Principles of fiscal and monetary policy', Journal of Monetary Economics 17, 117-134. 
Lucas, R. E. and Stokey, N. L. (1983), 'Optimal fiscal and monetary policy in an economy without capital', Journal of Monetary Economics 12(1), 55-93.

Marcet, A. and Scott, A. (2009), 'Debt and deficit fluctuations and the structure of bond markets', Journal of Economic Theory 144, 473-501.

Martin, F. M. (2009), 'A positive theory of government debt', Review of Economic Dynamics 12(4), 608-631.

Martin, F. M. (2011a), Government policy in monetary economies. Mimeo.

Martin, F. M. (2011b), 'On the joint determination of fiscal and monetary policy', Journal of Monetary Economics, forthcoming .

McGrattan, E. R. and Ohanian, L. E. (2010), 'Does neoclassical theory account for the effects of big fiscal shocks? Evidence from World War II', International Economic Review 51(2), 509-532.

Ohanian, L. E. (1997), 'The macroeconomic effects of war finance in the United States: World War II and the Korean War', American Economic Review 87(1), 23-40.

Ohanian, L. E. (1998), The Macroeconomic Effects of War Finance in the United States: Taxes, Inflation, and Deficit Finance, Routledge.

Ravn, M. O. and Uhlig, H. (2002), 'On adjusting the hodrick-prescott filter for the frequency of observations', The Review of Economics and Statistics 84(2), 371-376.

Shi, S. (2006), 'Viewpoint: A microfoundation of monetary economics', Canadian Journal of Economics 39(3), 643-688.

Shin, Y. (2007), 'Managing the maturity structure of government debt', Journal of Monetary Economics 54, 1565-1571.

Wallace, N. (1998), 'A dictum for monetary theory', Federal Reserve Bank of Minneapolis Quarterly Review 22(1), 20-26.

Wallace, N. (2001), 'Whither monetary economics?', International Economic Review 42(4), 847869.

Wallis, J. J. (2006a), Federal government expenditure, by major function: 1789-1970, in S. B. Carter, S. S. Gartner, M. R. Haines, A. L. Olmstead, R. Sutch and G. Wright, eds, 'Historical Statistics of the United States, Earliest Times to the Present: Millennial Edition', New York: Cambridge University Press.

Wallis, J. J. (2006b), Federal government finances - revenue, expenditure, and debt: 1789-1939, in S. B. Carter, S. S. Gartner, M. R. Haines, A. L. Olmstead, R. Sutch and G. Wright, eds, 'Historical Statistics of the United States, Earliest Times to the Present: Millennial Edition', New York: Cambridge University Press.

Williamson, S. and Wright, R. (2010), New monetarist economics: Models, in B. M. Friedman and M. Woodford, eds, 'Handbook of Monetary Economics', Vol. 3, North Holland, Amsterdam. 


\section{Appendix}

\section{A Periods with high defense expenditure due to wars}

Figure 4: Defense expenditure / GDP

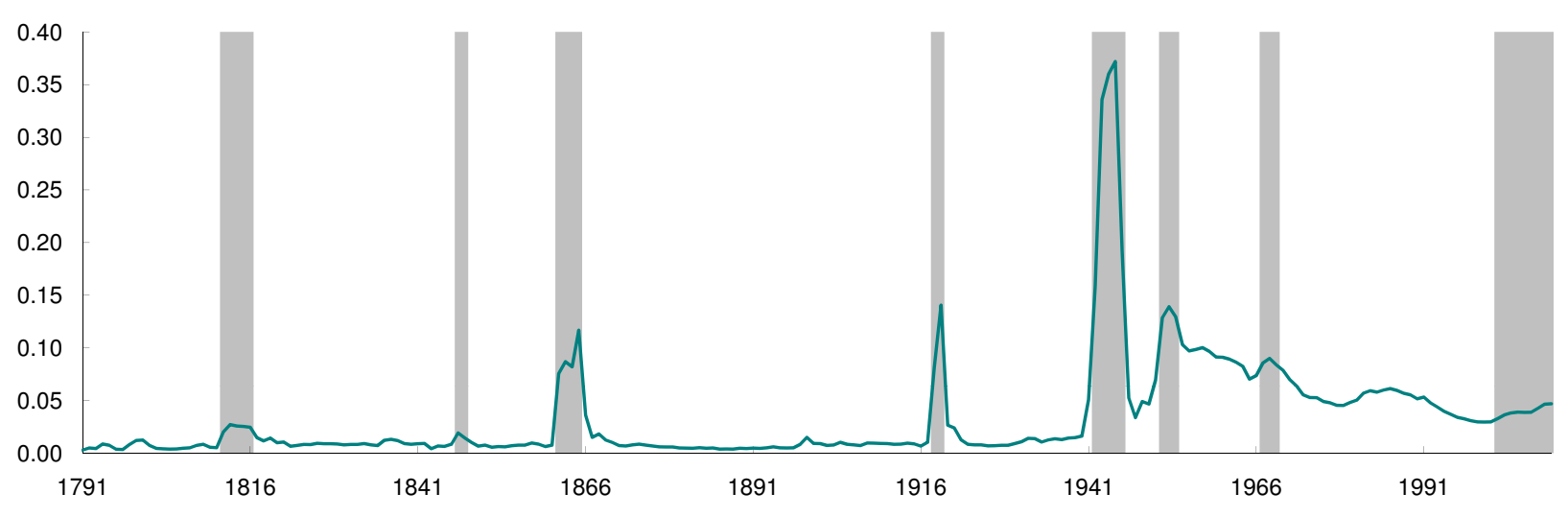

\section{B Derivation of equilibrium conditions (2)-(5)}

The problem of an agent at night can be written as

$$
W(z, B, \psi)=\max _{c, m^{\prime}, b^{\prime}} U(c)-\frac{\alpha c}{(1-\tau)}+\frac{\alpha\left(z-(1+\mu)\left(m^{\prime}+q b^{\prime}\right)\right)}{p(1-\tau)}+\psi v(g)+\beta E\left[V\left(m^{\prime}, b^{\prime}, B^{\prime}, \psi^{\prime}\right) \mid \psi\right] .
$$

The first-order conditions are

$$
\begin{aligned}
U_{c}-\frac{\alpha}{(1-\tau)} & =0 \\
-\frac{\alpha(1+\mu)}{p(1-\tau)}+\beta E\left[V_{m}^{\prime} \mid \psi\right] & =0 \\
-\frac{\alpha q(1+\mu)}{p(1-\tau)}+\beta E\left[V_{b}^{\prime} \mid \psi\right] & =0 .
\end{aligned}
$$

Focusing on a symmetric equilibrium, we can follow Lagos and Wright (2005) to show that (16) and (17) imply all agents exit the night market with the same money and bond balances. Furthermore, the value function $W$ is linear, $W_{z}=\frac{\alpha}{p(1-\tau)}$ and thus, $W(z, B, \psi)=W(0, B, \psi)+$ $\frac{\alpha z}{p(1-\tau)}$. We also get

$$
q=\frac{E\left[V_{b}^{\prime} \mid \psi\right]}{E\left[V_{m}^{\prime} \mid \psi\right]}
$$

A consumer in the day market enters the period with $m$ units of fiat money and $b$ units of government bonds. Being generally cash-constrained, he borrows $\ell$ units of fiat money from the bank with the obligation to repay $(1+i) \ell$ units of money at night. The consumer then uses $m+\ell$ to 
buy $x$ goods at price $\tilde{p}$. Thus, his starting nominal balances at night - net of loan obligations - are equal to $m+b-\tilde{p} x-i \ell$. Using $\xi$ as the Lagrange multiplier associated with the budget constraint, the problem of a consumer is

$$
V^{c}(m, b, B, \psi)=\max _{x, \ell} u(x)+W(0, B, \psi)+\frac{\alpha(m+b-\tilde{p} x-i \ell)}{p(1-\tau)}+\xi(m+\ell-\tilde{p} x) .
$$

The first-order conditions imply

$$
\begin{aligned}
\xi & =\frac{u_{x}}{\tilde{p}}-\frac{\alpha}{p(1-\tau)} \\
i & =\frac{u_{x} p(1-\tau)}{\alpha \tilde{p}}-1 .
\end{aligned}
$$

Note that $i=0$ if and only if $\xi=0$.

A producer has no use for cash and thus, deposits his money holdings at the bank. If he starts the period with $m$ units of money and $b$ units of government bonds, deposits $d$ units of money and sells $\kappa$ units of the day-good at price $\tilde{p}$, his starting nominal balances at night-including deposit claims - are $m+b+\tilde{p} \kappa+i d$. The problem of a producer can be written as

$$
V^{p}(m, b, B, \psi)=\max _{\kappa, d}-\phi \kappa+W(0, B, \psi)+\frac{\alpha(m+b+\tilde{p} \kappa+i d)}{p(1-\tau)}+\xi_{d}(m-d),
$$

where $\xi_{d}$ is the Lagrange multiplier associated with the constraint that states that an agent cannot deposit more than his fiat money holdings. The first-order conditions imply

$$
\begin{aligned}
\phi & =\frac{\alpha \tilde{p}}{p(1-\tau)} \\
\xi_{d} & =\frac{\alpha i}{p(1-\tau)} .
\end{aligned}
$$

The second equation shows that producers deposit all their money holdings if $i>0$. Without loss of generality, assume that they also deposit all their money holdings when $i=0$.

The market clearing conditions are $\eta \ell=(1-\eta) d$ and $(1-\eta) \tilde{p} \kappa=\eta(1+\ell)$. The first equation states that the total amount of money borrowed from banks has to equal the total amount of money that was deposited at banks. The second equation states that the nominal value of total output sold by producers has to equal total money holdings - including loans - of buyers. Note that since producers deposit all their money holdings, $d=1$ and thus, $\ell=\frac{1-\eta}{\eta}$, which implies $(1-\eta) \tilde{p} \kappa=1$. Using the day-resource constraint, $\eta x=(1-\eta) \kappa$, we get $\tilde{p}=\frac{1}{\eta x}$. Thus, the equilibrium in the day market is characterized by

$$
\begin{aligned}
i & =\frac{u_{x}}{\phi}-1 \\
\eta \phi x & =\frac{\alpha}{p(1-\tau)} .
\end{aligned}
$$

In addition, in a monetary equilibrium, $\xi \geq 0$, which implies $x\left(u_{x}-\phi\right) \geq 0$.

Finally, we derive the expressions for $V_{m}$ and $V_{b}$. Given $V(m, b, B, \psi) \equiv \eta V^{c}(m, b, B, \psi)+(1-$

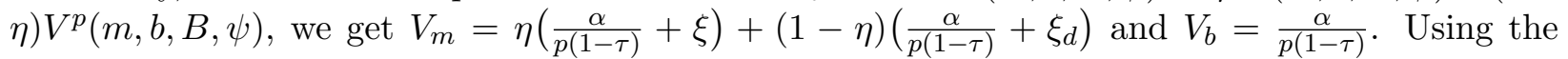
conditions derived above, we obtain $V_{m}=\eta u_{x} x$ and $V_{b}=\eta \phi x$. Note also that, from (20), $W_{z}=\eta \phi x$. We can now collect the equations characterizing agents' behavior in equilibrium. Conditions (15), (16), (18) and (20), plus the expressions for $V_{m}$ and $V_{b}$ updated one period, yield (2)-(5). 


\section{Proof of Proposition 1}

We will use the following auxiliary lemma.

Lemma $1 \lambda=0$ if and only if $\{\hat{x}, \hat{c}, \hat{g}(\psi)\}$ is implemented in all periods, for all $\psi \in \Psi$.

Proof. Suppose $\lambda=0$. Then, from (8), $x=\hat{x}$ and $\zeta=0$. From (9) and (10), we get $c=\hat{c}$ and $g=\hat{g}(\psi)$, for all $\psi$. From (7), we get $\lambda^{\prime} \equiv \Lambda\left(B^{\prime}, \psi^{\prime}\right)=0$, for all states, which from (8)-(10) implies $x^{\prime}=\hat{x}, c^{\prime}=\hat{c}$ and $g^{\prime}=\hat{g}\left(\psi^{\prime}\right)$, for all $\psi^{\prime}$. Suppose now that $x=x^{\prime}=\hat{x}, c=c^{\prime}=\hat{c}, g=\hat{g}(\psi)$ and $g^{\prime}=\hat{g}\left(\psi^{\prime}\right)$. Then, equations (8)-(10) all imply $\lambda=0$.

(i) Suppose not, i.e., $\lambda \equiv \Lambda(B, \psi)=0$ for some $B \in \Gamma, \psi \in \Psi$. Then, (8) becomes $\eta\left(u_{x}-\phi\right)+$ $\zeta u_{x x}=0$, which implies $\mathcal{X}(B, \psi)=\hat{x}$. From (9) and (10) we get $\mathcal{C}(B, \psi)=\hat{c}$ and $\mathcal{G}(B, \psi)=\hat{g}(\psi)$. From $(6), \mathcal{B}(B, \psi)=\frac{\alpha \hat{g}(\psi)}{\beta \eta \phi \hat{x}}+\frac{1+B}{\beta}-1>B$. By Lemma 1, the first-best allocation $\{\hat{x}, \hat{c}, \hat{g}(\psi)\}$ is also implemented in all future periods. Thus, the policy from the current period on is $\hat{\mu}=\beta-1$, $\hat{\tau}=0, \hat{q}=1$ and $\hat{p}=\frac{\alpha}{\eta \phi \hat{x}}$; the value function is $\mathcal{V}(B, \psi)=\hat{V}(\psi) \equiv \frac{\eta(u(\hat{x})-\phi \hat{x})+U(\hat{c})-\alpha \hat{c}}{1-\beta}+\hat{\omega}(\psi)$, where $\hat{\omega}(\psi) \equiv v(\hat{g}(\psi))-\alpha \hat{g}(\psi)+\beta E\left[\hat{\omega}\left(\psi^{\prime}\right) \mid \psi\right]$.

A day-market consumer arrives to the night market with nominal balances equal to $m+b-\tilde{p} \hat{x}-i l$. In equilibrium, we have $m=1, b=B, \tilde{p}=\frac{1}{\eta \hat{x}}$ and $i=0$. Thus, the consumer arrives with nominal balances $B-\frac{1-\eta}{\eta}$ and works $\hat{n}^{c}=\frac{\hat{c}}{1-\hat{\tau}}-\frac{B-\frac{1-\eta}{\eta}-(1+\hat{\mu})\left(m^{\prime}+\hat{q} b^{\prime}\right)}{\hat{p}(1-\hat{\tau})}=\hat{c}-\frac{\eta \phi \hat{x}\left(B-\frac{1-\eta}{\eta}-\beta\left(m^{\prime}+b^{\prime}\right)\right)}{\alpha}$. If he does not deviate, he chooses $m^{\prime}=1$ and $b^{\prime}=\mathcal{B}(B, \psi)$ and hence works $\hat{n}^{c}=\hat{c}+\hat{g}(\psi)+\frac{\phi \hat{x}}{\alpha}$. Thus, the equilibrium pay-off for a consumer at night is $\hat{W}^{c}(\psi)=-\phi \hat{x}+U(\hat{c})-\alpha(\hat{c}+\hat{g}(\psi))+v(\hat{g}(\psi))+$ $\beta E\left[\hat{V}\left(\psi^{\prime}\right) \mid \psi\right]$.

Consider now a consumer that deviates at night in the following way: he still consumes $\hat{c}$ and chooses $m^{\prime}=1$, but now he sells all his bonds, i.e., $b^{\prime}=0$ and saves on work accordingly. After the current period, the agent maintains a portfolio of zero bonds and finances his (firstbest) consumption with fiat money, deposits/loans and labor only. Thus, in future periods the agent works $n_{d}=\hat{c}+\frac{\eta \phi \hat{x}(\beta-z)}{\alpha}$. Note that expected nominal balances $z$ are equal to 1 and so, expected night-labor is $\hat{c}-\frac{\eta \phi \hat{x}(1-\beta)}{\alpha}$. The value of this continuation strategy is then $V_{d}(\psi)=$ $\frac{\eta(u(\hat{x})-\phi \hat{x})+U(\hat{c})-\alpha \hat{c}}{1-\beta}+\eta \phi \hat{x}+\omega_{d}(\psi)$, where $\omega_{d}(\psi)=v(\hat{g}(\psi))+\beta E\left[\omega_{d}\left(\psi^{\prime}\right) \mid \psi\right]$. In the deviation period, the consumer chooses $c=\hat{c}, m^{\prime}=1$ and $b^{\prime}=0$ and thus, works $n_{d}^{c}=\hat{c}+\frac{\eta \phi \hat{x}\left(\beta-B+\frac{1-\eta}{\eta}\right)}{\alpha}$. The pay-off from deviating is $W_{d}^{c}(\psi)=U(\hat{c})-\alpha \hat{c}-\eta \phi \hat{x}\left(\beta-B+\frac{1-\eta}{\eta}\right)+v(\hat{g}(\psi))+\beta E\left[V_{d}\left(\psi^{\prime}\right) \mid \psi\right]$. A consumer has an incentive to deviate only if $W_{d}^{c}(\psi)>\hat{W}^{c}(\psi)$.

Canceling common terms, $W_{d}^{c}(\psi)>\hat{W}^{c}(\psi)$ implies $\eta \phi \hat{x}(1+B-\beta)+\alpha \hat{g}(\psi)>\beta E\left[\hat{V}\left(\psi^{\prime}\right)-V_{d}\left(\psi^{\prime}\right) \mid\right.$ $\psi]$. Note that $\hat{V}(\psi)-V_{d}(\psi)=\hat{\omega}(\psi)-\eta \phi \hat{x}-\omega_{d}(\psi)$. We can write $\hat{\omega}(\psi)-\omega_{d}(\psi)=\varpi(\psi)$, where $\varpi(\psi) \equiv-\alpha \hat{g}(\psi)+\beta E\left[\varpi\left(\psi^{\prime}\right) \mid \psi\right]$. Thus, $\hat{V}(\psi)-V_{d}(\psi)=-\eta \phi \hat{x}-\alpha \hat{g}(\psi)+\beta E\left[\varpi\left(\psi^{\prime}\right) \mid \psi\right]$ and so, $W_{d}^{c}(\psi)>\hat{W}^{c}(\psi)$ simplifies to $\eta \phi \hat{x}(1+B)+\alpha \hat{g}(\psi)>\beta E\left[\varpi\left(\psi^{\prime}\right) \mid \psi\right]$. Given $\varpi(\psi)<0$ for all $\psi \in \Psi$, this conditions is satisfied for all $B \in \Gamma$. Thus, there is a profitable deviation from the equilibrium for any $B \in \Gamma$, a contradiction with $\Lambda(B, \psi)=0$ for some $B \in \Gamma, \psi \in \Psi$.

(ii) Given $\lambda \eta \phi(1+B) \geq 0$, (8) implies $\eta\left(u_{x}-\phi\right)+\zeta u_{x x} \geq 0$. Suppose $\eta\left(u_{x}-\phi\right)+\zeta u_{x x}=0$. Given $u_{x x}<0$, the only solution is $x=\hat{x}, \zeta=0$. Suppose now $\eta\left(u_{x}-\phi\right)+\zeta u_{x x}>0$. Then, the solution is $x<\hat{x}$ and $\zeta=0$. 
(iii) Suppose not, i.e., $\mathcal{X}_{B} \geq 0$ for some $B \in \Gamma, \psi \in \Psi$. Given $\zeta=0$, totally differentiating (8) with respect to $B$ implies: $u_{x x} \mathcal{X}_{B}=\Lambda_{B} \phi(1+B)+\lambda \phi$. Given $u_{x x}<0$ and $\mathcal{X}_{B} \geq 0$, the left-hand side of the expression above is weakly negative. Thus, $\Lambda_{B} \phi(1+B)+\lambda \phi \leq 0$, which, given $\lambda>0$, cannot be satisfied for $B=-1$ and implies $\Lambda_{B}<0$ for $B>-1$.

From (10), $\Lambda_{B}<0$ implies $\mathcal{G}_{B}>0$. From (9) and (10) we get $F(c, g ; \psi) \equiv \psi v_{g}\left(U_{c}-\alpha\right)+\left(\psi v_{g}-\right.$ $\alpha) U_{c c} c=0$. By the Implicit Function Theorem, $\frac{d c}{d g}=-\frac{F_{g}}{F_{c}}$. We get $F_{g}=\psi v_{g g}\left(U_{c}-\alpha+U_{c c} c\right)>0$, since from (9), $\lambda>0$ implies $U_{c}-\alpha+U_{c c} c<0$. Thus, to show $\frac{d c}{d g}>0$ and thus, $\mathcal{C}_{B}>0$, we need $F_{c}<0$. We get $F_{c}=\psi v_{g} U_{c c}+\left(\psi v_{g}-\alpha\right)\left(U_{c c}+U_{c c c} c\right)$, which using $F(c, g ; \psi)=0$ can be rewritten as $F_{c}=\frac{\psi v_{g}}{c}\left\{U_{c c} c-\left(U_{c}-\alpha\right)\left(1+\frac{U_{c c c} c}{U_{c c}}\right)\right\}$; by assumption, this expression is negative, which implies $\mathcal{C}_{B}>0$.

Given the above results, starting the period with a higher $B$ results in: (weakly) higher $x$ since $\mathcal{X}_{B} \geq 0$; higher $c$ and $g$ since $\mathcal{C}_{B}>0$ and $\mathcal{G}_{B}>0$; and a more relaxed budget constraint since $\Lambda_{B}>0$. This implies the government could increase welfare with an infinitesimal increase in debt, which contradicts $\mathcal{V}_{B}=-\lambda \eta \phi x<0$.

(iv) By (8) and parts (i) - (ii), $\mathcal{X}(-1, \psi)=\hat{x}$ and $\mathcal{X}(B, \psi)<\hat{x}$ for all $B>-1$.

Suppose $\mathcal{B}(B, \psi)=-1$ for some $B \in \Gamma, \psi \in \Psi$. Then (7) becomes $\phi \hat{x}\left(\lambda-E\left[\lambda^{\prime} \mid \psi\right]\right)+$ $\lambda \hat{u}_{x x} \hat{x} E\left[\mathcal{X}_{B}^{\prime} \mid \psi\right]=0$. Given parts (i) and (iii), $\lambda-E\left[\lambda^{\prime} \mid \psi\right]<0$. This last result holds regardless of whether the solution is interior or a corner. $\lambda<E\left[\lambda^{\prime} \mid \psi\right]$ rules out $B=-1$; hence, $\mathcal{B}(-1, \psi)>-1$ for all $\psi \in \Psi$. Next, focus on $B>-1$. For a given $\psi \in \Psi$, evaluating (6) today and tomorrow we get:

$$
\begin{aligned}
\left(U_{c}-\alpha\right) c-\alpha g-\eta \phi x(1+B) & =0 \\
\left(U_{c}^{\prime}-\alpha\right) c^{\prime}-\alpha g^{\prime}+\beta \eta E\left[x^{\prime \prime}\left(u_{x}^{\prime \prime}-\phi\right) \mid \psi^{\prime}\right]+\beta \phi E\left[x^{\prime \prime} \mid \psi^{\prime}\right]\left(1+B^{\prime \prime}\right) & =0, \forall \psi^{\prime} \in \Psi
\end{aligned}
$$

where $B^{\prime \prime} \equiv \mathcal{B}\left(-1, \psi^{\prime}\right)$ and $x^{\prime \prime} \equiv \mathcal{X}\left(B^{\prime \prime}, \psi^{\prime \prime}\right)$ for all $\psi^{\prime}, \psi^{\prime \prime} \in \Psi$.

Since $B>-1$, we get $\left(U_{c}-\alpha\right) c-\alpha g>0$. Since $B^{\prime \prime}>-1$ and $\mathcal{X}\left(B^{\prime \prime}, \psi^{\prime \prime}\right)<\hat{x}$ we get $\left(U_{c}^{\prime}-\alpha\right) c^{\prime}-\alpha g^{\prime}<0$. By the argument in part (iii) we know that $\frac{d c}{d g}>0$. Also note that $\left(U_{c}-\alpha\right) c$ is strictly decreasing in $c$ since from (9), $\lambda>0$ implies $U_{c}-\alpha+U_{c c} c<0$. Thus, $c<c^{\prime}$ and $g<g^{\prime}$, for all $\psi^{\prime} \in \Psi$. Now, from (9) and (10) we get $\tilde{F}(c, \nu) \equiv \nu\left(U_{c}-\alpha\right)+(\nu-\alpha) U_{c c} c=0$, where $\nu \equiv \psi v_{g}$. Given $\tilde{F}_{\nu}=U_{c}-\alpha+U_{c c} c<0$ and $\tilde{F}_{c}=F_{c}<0$, we get $\frac{d c}{d \nu}<0$. Thus, $\psi v_{g}>\psi^{\prime} v_{g}^{\prime}$ for all $\psi^{\prime} \in \Psi$. From (10) this implies $\lambda>E\left[\lambda^{\prime} \mid \psi\right]$, a contradiction.

Given $\mathcal{B}(B, \psi)>-1, \mathcal{X}\left(B^{\prime}, \psi^{\prime}\right)<\hat{x}$ for all $\psi, \psi^{\prime} \in \Psi$; thus, from $(5) q<1$.

\section{Numerical approximation of equilibrium policy functions}

The Markov-perfect equilibrium is approximated globally using a projection method as follows:

(i) Define a grid with 10 points over debt. Create the indexed functions $\mathcal{B}^{i}(B), \mathcal{X}^{i}(B), \mathcal{C}^{i}(B)$, and $\mathcal{G}^{i}(B)$, for $i=1, \ldots, N$. Set an initial guess.

(ii) Construct the following system of equations: for every point in the debt and $\psi$ grids, evaluate the four equations characterizing the Markov-perfect equilibrium, as per Definition 2. Note 
Figure 5: Government policy in the two-state case
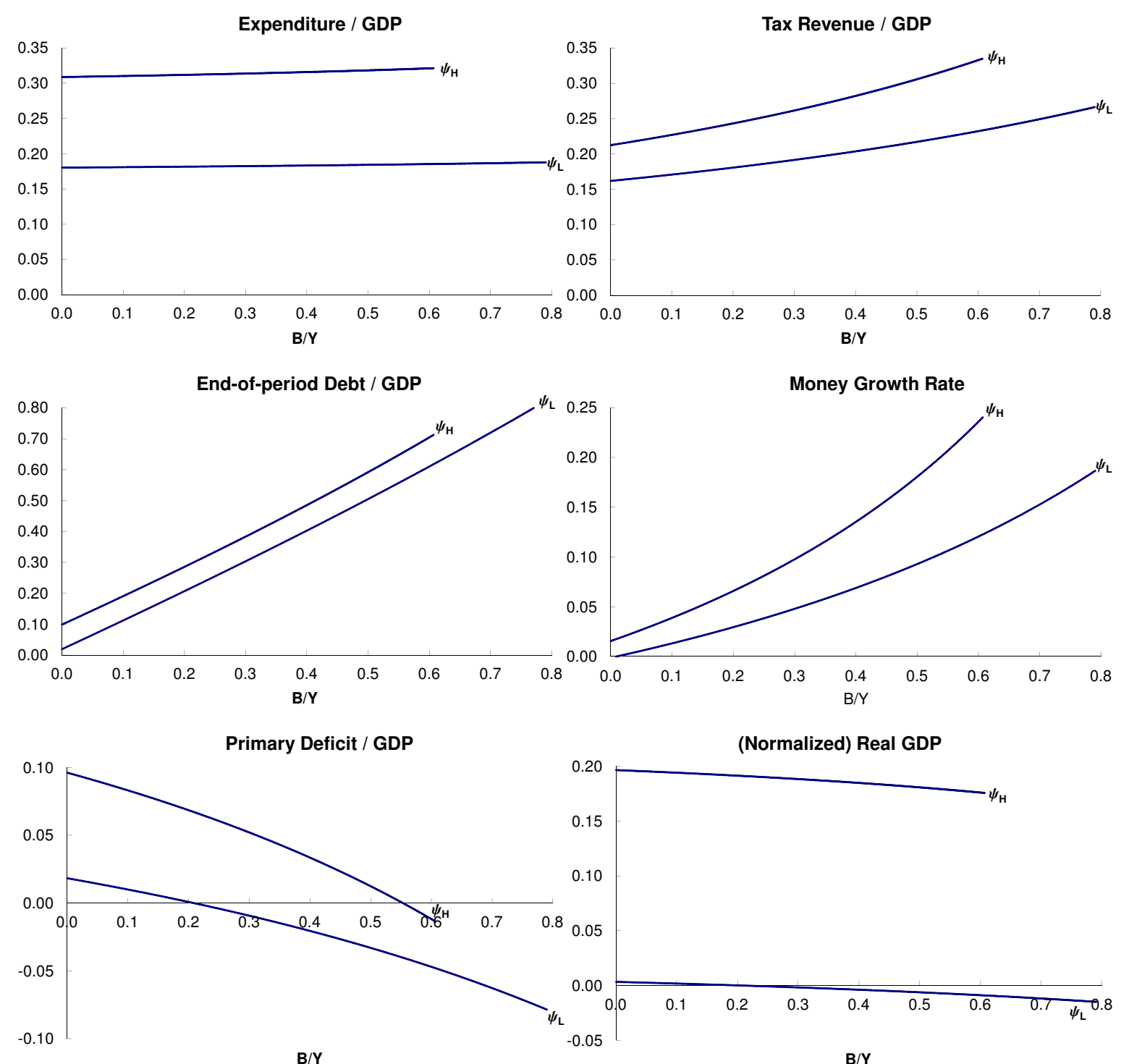

that these equations contain policy functions (and their derivatives), evaluated tomorrow. Use cubic splines to interpolate between debt grid points and calculate the derivatives of policy functions.

(iii) Use a non-linear equations solver to solve the system in (ii). There are $n \times 40$ equations. The unknowns are the values of the policy functions at the grid points. In each step of the solver, the associated cubic splines need to be updated so that the interpolated evaluations of future choices are consistent with each new guess. 
Since the Lagos-Wright model has two sectors, we need to construct measures of real GDP and the aggregate price level. In the model, real GDP is measured using the non-stochastic steady state as the base period for prices. Thus, let $y_{t}=\ln \left(\tilde{p}^{*} x_{t}+p^{*}\left(c_{t}+g_{t}\right)\right)$ be the measure of log real GDP in the artificial economy. To calculate the inflation rate, define the aggregate (normalized) price level $P$ as the weighted average of prices in the day and night markets. I.e., for any period $t$, let $P_{t} \equiv s_{D} \tilde{p}_{t}+s_{N} p_{t}$, where $s_{D}$ and $s_{N}$ are the expenditure shares for the day and night markets, respectively. Expenditure shares are constructed using the non-stochastic steady state statistics as the base period: $s_{D} \equiv \frac{\tilde{p}^{*} x^{*}}{Y^{*}}$ and $s_{N} \equiv \frac{p^{*}\left(c^{*}+g^{*}\right)}{Y^{*}}$. The inflation rate is defined as: $\pi_{t} \equiv \frac{P_{t}\left(1+\mu_{t-1}\right)}{P_{t-1}}-1$.

Figure 5 displays policy variables for the case with two expenditure states, $\psi_{l}$ and $\psi_{H}$. As we can see, the relationship between the primary deficit and debt-after controlling for expenditure shocks - is negative, which is consistent with the findings in Bohn (1998).

\section{E Alternative calibrations and comparative dynamics}

The calibration in Section 4.1 could have included more parameters. This section shows that doing so would not affect the results. Consider the following, more general, functional forms:

$$
\begin{aligned}
u(x) & =\varsigma \frac{x^{1-\sigma}-1}{1-\sigma} \\
f(x) & =\phi \frac{x^{\varphi}}{\varphi} \\
U(c) & =\varrho \frac{c^{1-\rho}-1}{1-\rho},
\end{aligned}
$$

where $f(x)$ is the (convex) production function in the day-market. The benchmark calibration normalizes $\varsigma=1, \varphi=1$ and $\varrho=1$. In addition, we have $\eta=0.5$. Note that we should keep $v(g)=\ln g$ since we want expenditure to be "flat" in debt, so that variations can be interpreted as exogenous - see Figure 5.

Consider varying parameter values by $20 \%$, one at a time. I.e., consider setting $\varsigma=1.2, \varphi=1.2$, $\varrho=1.2$ or $\eta=0.6$. Table 8 shows that, except in the case of $\varphi$, changing one parameter at a time and re-calibrating implies a change in just one other parameter. Changing $\varsigma$ or $\eta$ affects only $\phi$, while changing $\varrho$ affects only $\alpha$. In contrast, varying $\varphi$ affects all parameters except for $\beta$. In all cases, all calibration targets are matched identically. In addition, velocity of circulation $Y^{*}$ and the relative size of the day-market, which are not targets, are identical for all calibrations. Table 8 also shows the averages of the 10,000,000 simulations, similar to Table 4, for the case with three expenditure states. As we can see, the benchmark and all four alternative calibrations are virtually indistinguishable.

Alternatively, consider changing parameters as above, but without re-calibrating, which gives an idea of what we could gain in terms of dynamics at the expense of a poorer long-run fit. In all cases, we obtain similar steady state statistics for inflation, deficit and the nominal interest rate. Differences appear in debt over GDP, expenditure over GDP and revenue over GDP. Table 9 summarizes the resulting dynamics, by focusing on war peaks vs pre-war averages, as in Table 4, again for the case with three expenditure states. Charts similar to Figure 2 for all these cases are available upon request. Although the changes in parameters are large, there is not much variation 
Table 8: Alternative calibrations

\begin{tabular}{|l|c|c|c|c|c|}
\hline & Benchmark & $\varsigma=1.2$ & $\varphi=1.2$ & $\varrho=1.2$ & $\eta=0.6$ \\
\hline Parameters & 4.1722 & & 4.0401 & 4.0677 & \\
\hline$\alpha$ & 0.9728 & & & & \\
$\rho$ & 8.1879 & & 9.7810 & & \\
$\sigma$ & 2.5084 & & 2.8100 & & \\
$\phi$ & 4.8290 & 4.2792 & 4.8656 & & 3.5660 \\
\hline War peak vs 5-year pre-war average \\
\hline Outlays/GDP & 0.211 & 0.211 & 0.212 & 0.211 & 0.211 \\
Revenue/GDP & 0.115 & 0.115 & 0.115 & 0.115 & 0.115 \\
Deficit/GDP & 0.128 & 0.128 & 0.128 & 0.128 & 0.128 \\
Debt/GDP & 0.300 & 0.301 & 0.300 & 0.301 & 0.300 \\
Inflation & 0.128 & 0.130 & 0.129 & 0.128 & 0.131 \\
GDP & 0.275 & 0.275 & 0.278 & 0.275 & 0.275 \\
\hline
\end{tabular}

Note: Parameters are at benchmark, except where noted. All calibrations match the targets on Table 2.

in the behavior of variables. Notice that variations in the primary deficit are almost identical in all cases.

The largest effect is for the case when $\varphi=1.2$. Here, we get larger increases in revenue and inflation, and a smaller average increase in debt. For revenue and debt, this calibration would provide a worse fit relative to the average performance in the three big U.S. wars. On the other hand, inflation would be closer, but note that this figure is biased upward by the Civil War - see Table 1. In terms of model performance during World War II, the calibration with $\varphi=1.2$ would exacerbate the overreliance on revenue and inflation, and under-predict the increase in debt (in addition to failing to match long-run averages). Since the function $f(x)$ needs to be convex, the assumed linearity in the benchmark calibration is still the best option.

Table 9: Comparative dynamics-War peak vs 5-year pre-war average

\begin{tabular}{|l|c|c|c|c|c|}
\hline & Benchmark & $\varsigma=1.2$ & $\varphi=1.2$ & $\varrho=1.2$ & $\eta=0.6$ \\
\hline Outlays/GDP & 0.211 & 0.210 & 0.213 & 0.210 & 0.208 \\
Revenue/GDP & 0.115 & 0.112 & 0.124 & 0.113 & 0.109 \\
Deficit/GDP & 0.128 & 0.128 & 0.122 & 0.128 & 0.129 \\
Debt/GDP & 0.300 & 0.305 & 0.264 & 0.300 & 0.310 \\
Inflation & 0.128 & 0.123 & 0.150 & 0.126 & 0.116 \\
GDP & 0.275 & 0.272 & 0.277 & 0.272 & 0.267 \\
\hline
\end{tabular}

Note: All parameters are at benchmark, except as specified on each column. Economies are not re-calibrated.

For the other alternative parameterizations, the differences are not large enough to matter for the results and any gains in fit would be heavily offset by the worse match in long-run averages. 